Article

\title{
The Influence of the Expansive Grout on Theoretical Bandwidth for the Measurement of Strain Waves by Borehole Tensor Strainmeters
}

\author{
Kanghua Zhang ${ }^{1,2}$, Jiayong Tian ${ }^{1, *}$ and Zhifei $\mathrm{Hu}^{1}$ \\ 1 Institute of Crustal Dynamics, China Earthquake Administration, P.O. Box 2855, Beijing 100085, China; \\ khzhang@tju.edu.cn (K.Z.); huzhifei17@mails.ucas.edu.cn (Z.H.) \\ 2 School of Civil Engineering, Tianjin University, Tianjin 300072, China \\ * Correspondence: chenlitedtian@263.net; Tel.: +0086-(0)10-62913587
}

Received: 26 March 2020; Accepted: 28 April 2020; Published: 4 May 2020

\begin{abstract}
The scattering model of incident seismic waves by an empty borehole has been presented to investigate the theoretical frequency response and the corresponding bandwidth of borehole tensor strainmeters. Inner-diameter changes of the stainless steel instrument casing are measured by horizontal extensometers (gauges), after the borehole tensor strainmeter is installed at a certain depth of the borehole and boned by expansive grout with the surrounding rock. There is, however, no answer for the difference between this case and the empty case. In this paper, the scattering model of incident elastic seismic waves by a two-ring borehole is introduced to investigate the influence of the expansive grout on theoretical bandwidth for the measurement of strain waves by borehole tensor strainmeters. The calculation of wave fields in the surrounding rock and the two rings by wave function expansion gives the inner-diameter changes of the stainless steel instrument casing. Several cases show that the mechanical parameters of the expansive grout have great influence on the frequency responses of borehole tensor strainmeters for different gauge combinations, but little influence on the bandwidth, which means that the high-frequency bandwidth promises the quantitative measurability of strain waves in the acoustical frequency range for borehole tensor strainmeters.
\end{abstract}

Keywords: seismic waves; frequency bandwidth; expansive grout; borehole tensor strainmeters

\section{Introduction}

In order to capture gentle tectonic strain caused by volcanic activity [1], fault failure process [2-9], etc., high-sensitivity borehole tensor strainmeters, such as RZB strainmeter [5], YRY strainmeter [10], and GTSM (Gladwin Tensor Strainmeter) strainmeter [11,12], have been developed and installed in Plate Boundary Observatory (PBO) [13-17] and the China Borehole Strainmeter Network [18,19]. The expansive grout cements the strainmeter to the borehole, which changes the strain that is in the rock to the diameter change of the stainless steel instrument casing. These diameter changes measured by four gauges of different orientation give the instrumental strains. The coupled parameters between the strain in the rock and instrumental strains must be calibrated in situ, which is usually done by comparison between instrumental strains and the calculated strain from theoretical earth tide $[14,16]$. Theoretical earth tide, though, is influenced by the deep structure of the Earth, the model of the ocean load both near and far from the coast, and topographic and geologic effects, which will induce the evident error in the calibration $[14,17,20,21]$. In order to increase the precision of in situ calibration for borehole tensor strainmeters, the combination of measured particle velocity from collocated borehole seismometers and local phase velocity yields the referenced strain-wave signal for high-precision, in situ calibration of borehole tensor strainmeters $[8,22-26]$. The dynamic couple relation between the 
referenced strain wave from the seismometer and the measured instrumental strain wave from the borehole tensor strainmeter must be provided for this attractive in situ calibration of the borehole tensor strainmeter, which has not been investigated yet. [27]

The scattering model of incident seismic waves by an empty borehole has been presented to investigate the theoretical frequency response and the corresponding bandwidth of borehole tensor strainmeters [27]. Inner-diameter changes of the stainless steel instrument casing are measured by horizontal extensometers (gauges), after the borehole tensor strainmeter is installed at a certain depth of the borehole and boned by expansive grout with the surrounding rocks. There is, however, no answer for the difference between this case and the empty case. Concerning the uncontrollability of the mechanical parameters of the expansive grout, it is necessary to discuss the influence of these mechanical parameters of the expansive grout in guaranteeing accuracy in determining bandwidth.

In this paper, the model of the incident elastic $\mathrm{P} / \mathrm{S}$ waves scattering by a two-ring borehole is introduced to investigate the theoretical frequency response between the referenced strain wave and the measured instrumental strain wave, and the corresponding bandwidth of borehole tensor strainmeters for measuring strain waves quantitatively. The influence of the mechanical parameters of the expansive grout on the frequency response and bandwidth of borehole tensor strainmeters for the gauge combinations are discussed in detail.

\section{The Model of Incident Elastic Wave Scattering by a Two-Ring Borehole}

A scattering model of an incident plane elastic $\mathrm{P}$ or $\mathrm{S}$ wave by a two-ring borehole in an infinite space is given to investigate theoretical frequency response and the corresponding bandwidth for borehole tensor strainmeters, as shown in Figure 1, where the two rings represent the instrument casing and the expansive grout, respectively. The inner radius and outer radius of the stainless steel instrument casing and the radius of the borehole are $a, b$, and $c$, respectively. The harmonic plane elastic $\mathrm{P}$ or $\mathrm{S}$ wave propagating in the plane perpendicular to the axis of the borehole is incident at the incident angle $\alpha$ with respect to the $x$ direction. Because of the existence of the borehole, grout and instrument casing, two kinds of scattering waves or standing waves (P and $\mathrm{S}$ waves) are generated from layer interfaces. The displacement $\mathbf{u}$ induced by total wave fields around the borehole, which include the incident and scattering wave fields, can be represented in terms of displacement potential $\phi$ of $\mathrm{P}$ wave and displacement potential $\psi$ of $S$ wave [28]:

$$
\mathbf{u}=\nabla \phi+\nabla \times\left(\mathbf{e}_{\mathbf{z}} \psi\right)
$$

where $\mathbf{e}_{\mathbf{z}}$ is a unit vector along the borehole axis.

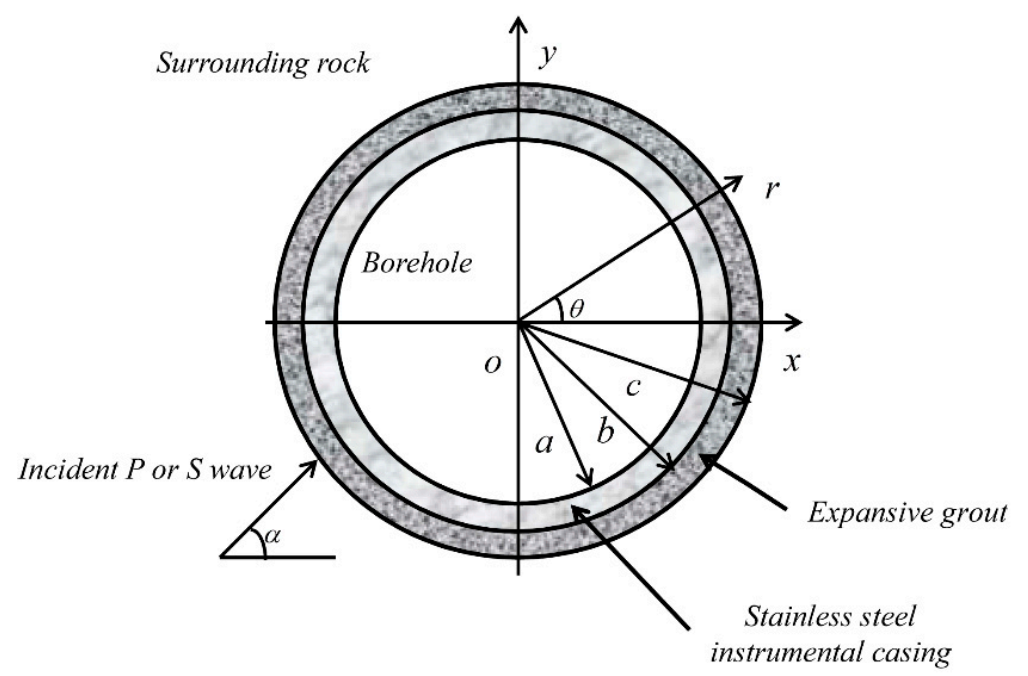

Figure 1. The scattering model of the incident elastic plane wave by a two-ring borehole. 
The incident $\mathrm{P}$ and $\mathrm{S}$ waves in the rock can be expressed in the form of displacement potential as:

$$
\begin{aligned}
& \left.\begin{array}{rl}
\varphi_{p}^{(i)} & =\varphi_{0} e^{i\left(k_{11} r \cos (\theta-\alpha)-\omega t\right)} \\
& =\varphi_{0} \sum_{n=-\infty}^{\infty} i^{n} J_{n}\left(k_{11} r\right) e^{i n(\theta-\alpha)} e^{-i \omega t}
\end{array}\right\}, \text { for the incident } P \text { wave } \\
& \left.\begin{array}{rl}
\psi_{S}^{(i)} & =\psi_{0} e^{i\left(k_{21} r \cos (\theta-\alpha)-\omega t\right)} \\
& =\psi_{0} \sum_{n=-\infty}^{\infty} i^{n} J_{n}\left(k_{21} r\right) e^{i n(\theta-\alpha)} e^{-i \omega t}
\end{array}\right\} \text {, for the incident } S \text { wave }
\end{aligned}
$$

where $k_{11}=\omega / c_{1 p}$ and $k_{21}=\omega / c_{1 s}$ are the wave number of the incident $\mathrm{P}$ and $\mathrm{S}$ waves, respectively. $c_{1 p}=\sqrt{\left(\lambda_{1}+2 \mu_{1}\right) / \rho_{1}}$ and $c_{1 s}=\sqrt{\mu_{1} / \rho_{1}}$ are $\mathrm{P}$ and $\mathrm{S}$ wave velocities in the surrounding rock, respectively. $\rho_{1}$ is the mass density of the surrounding rock. $\varphi_{0}$ and $\psi_{0}$ are the amplitudes of the incident $\mathrm{P}$ and $\mathrm{S}$ wave displacement potentials, respectively. $\omega$ is the circular frequency of the incident wave. $J_{n}$ denotes Bessel function of the first kind of order $n$. If no borehole, the incident wave-induced strains at the borehole center, along the propagation direction of incident $\mathrm{P} / \mathrm{S}$ waves, are expressed as:

$$
\begin{aligned}
& \left.\begin{array}{c}
\varepsilon_{x^{\prime}}^{(i)}=-\varphi_{0} k_{11}^{2} e^{-i \omega t} \\
\varepsilon_{y^{\prime}}^{(i)}=\varepsilon_{x^{\prime} y^{\prime}}^{(i)}=0
\end{array}\right\} \text {, for the incident P wave } \\
& \left.\begin{array}{c}
\varepsilon_{x^{\prime}}^{(i)}=\varepsilon_{y^{\prime}}^{(i)}=0 \\
\varepsilon_{x^{\prime} y^{\prime}}^{(i)}=\frac{1}{2} \psi_{0} k_{21}^{2} e^{-i \omega t}
\end{array}\right\} \text {, for the incident } S \text { wave }
\end{aligned}
$$

The scattering wave fields in the rock, grout layer and instrument casing layer can be denoted by wave functions of Bessel function or Hankel functions, with the unknown constants as following [28]:

$$
\begin{aligned}
& \left.\begin{array}{l}
\varphi_{1}^{(s)}=\sum_{n=-\infty}^{\infty} A_{n}^{1} H_{n}\left(k_{11} r\right) e^{i n(\theta-\alpha)} e^{-i \omega t} \\
\psi_{1}^{(s)}=\sum_{n=-\infty}^{\infty} C_{n}^{1} H_{n}\left(k_{21} r\right) e^{i n(\theta-\alpha)} e^{-i \omega t}
\end{array}\right\}, \text { for the surrounding rock } \\
& \left.\begin{array}{l}
\varphi_{2}^{(s)}=\sum_{n=-\infty}^{\infty} A_{n}^{2} H_{n}\left(k_{12} r\right) e^{i n(\theta-\alpha)} e^{-i \omega t}+B_{n}^{2} H_{n}\left(k_{12} r\right) e^{i n(\theta-\alpha)} e^{-i \omega t} \\
\psi_{2}^{(s)}=\sum_{n=-\infty}^{\infty} C_{n}^{2} H_{n}\left(k_{22} r\right) e^{i n(\theta-\alpha)} e^{-i \omega t}+D_{n}^{2} H_{n}\left(k_{22} r\right) e^{i n(\theta-\alpha)} e^{-i \omega t}
\end{array}\right\}, \text { for the grout layer } \\
& \left.\begin{array}{l}
\varphi_{3}^{(s)}=\sum_{n=-\infty}^{\infty} A_{n}^{3} H_{n}\left(k_{13} r\right) e^{i n(\theta-\alpha)} e^{-i \omega t}+B_{n}^{3} H_{n}\left(k_{13} r\right) e^{i n(\theta-\alpha)} e^{-i \omega t} \\
\psi_{3}^{(s)}=\sum_{n=-\infty}^{\infty} C_{n}^{3} H_{n}\left(k_{23} r\right) e^{i n(\theta-\alpha)} e^{-i \omega t}+D_{n}^{3} H_{n}\left(k_{23} r\right) e^{i n(\theta-\alpha)} e^{-i \omega t}
\end{array}\right\}, \text { for the instrument casing }
\end{aligned}
$$

where $k_{1 *}=\omega / c_{* p}$ and $k_{2 *}=\omega / c_{* S}$ are wave numbers of scattering P and S waves in the corresponding layers, respectively.

Substituting total wave fields, including the incident wave fields and the scattering wave fields, into the traction-free boundary conditions at the inner wall of the instrument casing and the continuity of stress and displacement at the borehole-grout and grout-instrument casing interfaces obtains the unknown constants, and then radial displacement at the inner wall of the instrument casing $\left.u_{r}\right|_{r=a}$.

The diameter change of the inner wall of the instrument casing, measured by the first gauge at azimuth angle $\theta_{1}$ in borehole tensor strainmeters, can be expressed by

$$
U_{r}\left(\theta_{1}\right)=\frac{\left.u_{r}\left(\theta_{1}\right)\right|_{r=a}+\left.u_{r}\left(\theta_{1}+180^{\circ}\right)\right|_{r=a}}{2 a}
$$


Similar to the scattering model of the incident elastic waves by an empty model, theoretical frequency responses $F V_{2}, F V_{4}, T V, F S$ and $T S$ of borehole tensor strainmeters are introduced as follows,

$$
\left.\begin{array}{l}
F V_{2}=\frac{U_{r}\left(\theta_{1}\right)+U_{r}\left(\theta_{1}+90^{\circ}\right)}{\Delta} \\
F V_{4}=\frac{U_{r}\left(\theta_{1}\right)+U_{r}\left(\theta_{1}+45^{\circ}\right)+U_{r}\left(\theta_{1}+90^{\circ}\right)+U_{r}\left(\theta_{1}+135^{\circ}\right)}{\Delta} \\
T V=\frac{U_{r}\left(\theta_{1}\right)+U_{r}\left(\theta_{1}+60^{\circ}\right)+U_{r}\left(\theta_{1}+120^{\circ}\right)}{\Delta} \\
F S=\frac{U_{r}\left(\theta_{1}\right)-U_{r}\left(\theta_{1}+90^{\circ}\right)}{\Delta} \\
T S=\frac{U_{r}\left(\theta_{1}+60^{\circ}\right)-U_{r}\left(\theta_{1}+120^{o}\right)}{\Delta}
\end{array}\right\},
$$

where $\Delta=\left\{\begin{array}{cl}\varepsilon_{x^{\prime}}^{(i)}=-\varphi_{0} k_{1}^{2} e^{-i \omega t} & \text { for the incident } \mathrm{P} \text { wave } \\ \varepsilon_{x^{\prime} y^{\prime}}^{(i)}=\frac{1}{2} \psi_{0} k_{2}^{2} e^{-i \omega t} & \text { for the incident } \mathrm{S} \text { wave }\end{array}\right.$. Zero-frequency responses for $F V_{2}, F S$, and $T V$ reflect the far-field areal strain representing a strain invariant. Zero-frequency responses for $F S$ and TS reflect the maximum far-field shear strain not representing a strain invariant.

\section{Results and Discussions}

Here, a borehole of radius $c=65 \mathrm{~mm}$, expansive grout layer of $11.5 \mathrm{~mm}$ thickness, and instrument casing of $2 \mathrm{~mm}$ thickness are taken as an example to discuss the frequency responses of borehole tensor strainmeters and corresponding bandwidth. Poisson ratios of the rock and instrument casing are $v_{1}=0.25$ and $v_{3}=0.30$, respectively. The corresponding Young's moduli are taken as $E_{1}=50 \mathrm{GPa}$ and $E_{3}=196 \mathrm{GPa}$, respectively, and the densities are taken as $\rho_{1}=2.5 \mathrm{~g} / \mathrm{cm}^{3}$ and $\rho_{3}=7.85 \mathrm{~g} / \mathrm{cm}^{3}$, respectively. During borehole tensor strainmeter installation at a certain depth, expansive grout is used to bond the borehole tensor strainmeter and the surrounding rocks. Due to the invisibility underground, it is difficult to control the mechanical parameters of the expansive grout. Besides, the mechanical parameters of the expansive grout are changing over time. To discuss the influence of the mechanical parameters of the expansive grout, we take the Poisson ratios of the grout in the range of $v_{2}=0.15 \sim 0.35$; the range of corresponding Young's moduli is $E_{2}=20 \mathrm{GPa} \sim 40 \mathrm{GPa}$, and the range of density is $\rho_{2}=1.6 \mathrm{~g} / \mathrm{cm}^{3} \sim 3.2 \mathrm{~g} / \mathrm{cm}^{3}$ [29]. Because frequency responses are influenced by the incident wave frequency and the difference between the first gauge at azimuth angle $\theta_{1}$ and the incident angle $\alpha, \alpha$ is set to zero to simplify the analysis.

\subsection{Incident $P$ Wave}

Figure 2 gives the theoretical amplitude spectrum of gauge combination $F V_{2}$ for borehole tensor strainmeters. The amplitude of $F V_{2}$ increases from zero-frequency gain (the values of gauge combinations at $f=0$ ) with the increase of incident wave frequency $f$, and reaches a peak value at a certain $f$, then roll-offs (an indicator of decay rate) at a certain approximate $\mathrm{dB} /$ decade of $f$, which is similar to the frequency responses of second-order low pass filters of a certain quality factor. Because the peak value is about than $10 \%$ larger compared with zero-frequency gain, it will not satisfy the $1 \%$ specification of $3 \mathrm{~dB}$ bandwidth waviness. The $1 \%$ bandwidth definition is adopted to determine the bandwidth of gauge combinations, where the cut-off frequency is taken when the amplitude spectrum is $101 \%$ compared with zero-frequency gain. The $1 \%$ bandwidth for $F V_{2}$ is $1214 \mathrm{~Hz}$. We also compared the theoretical amplitude spectrum of gauge combination $F V_{2}$ for the borehole tensor strainmeter with those for the empty borehole without grout and instrument casing, shown in Figure 2. The existence of grout and stainless steel casing will decrease the zero-frequency and peak value of $F V_{2}$, and shift the corresponding $f$ for peak value right relative to the empty borehole, which means the increase of resonance frequency of the empty borehole in infinite space. The response spectrums of $F V_{4}, F S$, $T V$ and $T S$ are similar to that of $F V_{2}$, but have different zero-frequency gains, peak values, $f$ for peak values, roll-offs and bandwidth. Table 1 shows characteristic values for the incident $P$ wave amplitude spectrum of $F V_{2}, F V_{4}, F S, T V$ and TS at different $\theta_{1}$. The gauge combinations, which reflect the far-field 
areal strain that represents a strain invariant, have the same change characteristics, while TS also has the same change characteristics as FS.

Table 1. Characteristic values for the incident $\mathrm{P}$ wave amplitude spectrum of $F V_{2}, F V_{4}, F S, T V$ and $T S$ at different $\theta_{1}$.

\begin{tabular}{|c|c|c|c|c|c|c|c|}
\hline & \multirow{2}{*}{$\theta_{1}\left({ }^{\circ}\right)$} & \multicolumn{6}{|c|}{$E_{2}=30 \mathrm{GPa}, v_{2}=0.25, \rho_{2}=2.4 \mathrm{~g} / \mathrm{cm}^{3}$} \\
\hline & & $\begin{array}{c}\text { Zero } \\
\text { Frequency Gain }\end{array}$ & $\begin{array}{l}\text { Peak } \\
\text { Value }\end{array}$ & $\begin{array}{l}f \text { for Peak } \\
\text { Value }\end{array}$ & $\begin{array}{l}\text { Roll-off } \\
\mathrm{dB} / \mathrm{dec}\end{array}$ & $\begin{array}{c}1 \% \\
\text { Bandwidth }\end{array}$ & $\begin{array}{c}f \text { for } 1 \% \\
\text { Bandwidth }\end{array}$ \\
\hline \multirow{7}{*}{$F V_{2}$} & 0 & $2.78(3.00)$ & $3.05(3.26)$ & $5543(5121)$ & $7.33(7.98)$ & $2.81(3.03)$ & $1214(1199)$ \\
\hline & 15 & $2.78(3.00)$ & $3.06(3.27)$ & $5598(5173)$ & $6.95(7.54)$ & $2.81(3.03)$ & $1207(1194)$ \\
\hline & 30 & $2.78(3.00)$ & $3.08(3.28)$ & $5709(5278)$ & $6.23(6.71)$ & $2.81(3.03)$ & $1194(1185)$ \\
\hline & 45 & $2.78(3.00)$ & $3.09(3.29)$ & $5765(5331)$ & $5.89(6.32)$ & $2.81(3.03)$ & $1188(1180)$ \\
\hline & 60 & $2.78(3.00)$ & $3.08(3.28)$ & $5709(5278)$ & $6.23(6.71)$ & $2.81(3.03)$ & $1194(1185)$ \\
\hline & 75 & $2.78(3.00)$ & $3.06(3.27)$ & $5598(5173)$ & $6.95(7.54)$ & $2.81(3.03)$ & $1207(1194)$ \\
\hline & 90 & $2.78(3.00)$ & $3.05(3.26)$ & $5543(5121)$ & $7.33(7.98)$ & $2.81(3.03)$ & $1214(1199)$ \\
\hline \multirow{7}{*}{ FS } & 0 & $2.90(3.00)$ & $3.33(3.33)$ & 3885 (3533) & $8.33(8.42)$ & $2.95(3.04)$ & $926(905)$ \\
\hline & 15 & $2.51(2.60)$ & $2.89(2.88)$ & 3885 (3533) & $8.35(8.43)$ & $2.53(2.63)$ & $926(905)$ \\
\hline & 30 & $1.45(1.50)$ & $1.67(1.66)$ & 3885 (3533) & $8.40(8.45)$ & $1.46(1.53)$ & $926(905)$ \\
\hline & 45 & $0(0)$ & $0(0)$ & $0(0)$ & $0(0)$ & $0(0)$ & $0(0)$ \\
\hline & 60 & $1.45(1.50)$ & $1.67(1.66)$ & 3885 (3533) & $8.30(8.45)$ & $1.46(1.52)$ & $926(905)$ \\
\hline & 75 & $2.51(2.60)$ & $2.88(2.88)$ & 3885 (3533) & $8.32(8.43)$ & $2.54(2.63)$ & $926(905)$ \\
\hline & 90 & $2.90(3.00)$ & $3.33(3.33)$ & 3885 (3533) & $8.33(8.42)$ & $2.93(3.04)$ & $926(905)$ \\
\hline \multirow{7}{*}{$F V_{4}$} & 0 & $2.78(3.00)$ & $3.07(3.27)$ & $5654(5226)$ & $6.59(7.12)$ & $2.81(3.03)$ & 1200 (1189) \\
\hline & 15 & $2.78(3.00)$ & 3.07 (3.27) & $5654(5226)$ & $6.59(7.12)$ & $2.81(3.03)$ & 1200 (1189) \\
\hline & 30 & $2.78(3.00)$ & 3.07 (3.27) & $5654(5226)$ & $6.59(7.12)$ & $2.81(3.03)$ & 1200 (1189) \\
\hline & 45 & $2.78(3.00)$ & $3.07(3.27)$ & $5654(5226)$ & $6.59(7.12)$ & $2.81(3.03)$ & 1200 (1189) \\
\hline & 60 & $2.78(3.00)$ & $3.07(3.27)$ & 5654 (5226) & $6.59(7.12)$ & $2.81(3.03)$ & 1200 (1189) \\
\hline & 75 & $2.78(3.00)$ & 3.07 (3.27) & $5654(5226)$ & $6.59(7.12)$ & $2.81(3.03)$ & 1200 (1189) \\
\hline & 90 & $2.78(3.00)$ & $3.07(3.27)$ & $5654(5226)$ & $6.59(7.12)$ & $2.81(3.03)$ & 1200 (1189) \\
\hline \multirow{7}{*}{$T V$} & 0 & $4.18(4.50)$ & $4.60(4.91)$ & $5654(5226)$ & $6.59(7.12)$ & $4.22(4.55)$ & 1200 (1189) \\
\hline & 15 & $4.18(4.50)$ & $4.60(4.91)$ & $5654(5226)$ & $6.59(7.11)$ & $4.22(4.55)$ & 1200 (1189) \\
\hline & 30 & $4.18(4.50)$ & $4.60(4.91)$ & $5654(5226)$ & $6.59(7.12)$ & $4.22(4.55)$ & 1200 (1189) \\
\hline & 45 & $4.18(4.50)$ & $4.60(4.91)$ & $5654(5226)$ & $6.59(7.13)$ & $4.22(4.55)$ & 1200 (1189) \\
\hline & 60 & $4.18(4.50)$ & $4.60(4.91)$ & $5654(5226)$ & $6.59(7.12)$ & $4.22(4.55)$ & 1200 (1189) \\
\hline & 75 & $4.18(4.50)$ & $4.60(4.91)$ & $5654(5226)$ & $6.59(7.11)$ & $4.22(4.55)$ & 1200 (1189) \\
\hline & 90 & $4.18(4.50)$ & $4.60(4.91)$ & $5654(5226)$ & $6.59(7.12)$ & $4.22(4.55)$ & 1200 (1189) \\
\hline \multirow{7}{*}{$T S$} & 0 & $0(0)$ & $0(0)$ & $0(0)$ & $0(0)$ & $0(0)$ & $0(0)$ \\
\hline & 15 & $1.26(1.30)$ & 1.45 (1.44) & 3605 (3578) & $6.91(6.79)$ & 1.27 (1.32) & 919 (901) \\
\hline & 30 & $2.17(2.25)$ & $2.51(2.50)$ & 3884 (3559) & $7.49(7.44)$ & $2.20(2.28)$ & $922(903)$ \\
\hline & 45 & $2.51(2.60)$ & $2.89(2.88)$ & 3856 (3533) & $8.33(8.43)$ & $2.54(2.63)$ & $926(905)$ \\
\hline & 60 & $2.17(2.25)$ & $2.51(2.49)$ & 3884 (3507) & $7.49(9.56)$ & $2.20(2.28)$ & $931(908)$ \\
\hline & 75 & $1.26(1.30)$ & $1.45(1.44)$ & 3605 (3488) & $6.91(10.48)$ & $1.27(1.32)$ & 934 (909) \\
\hline & 90 & $0(0)$ & $0(0)$ & $0(0)$ & $0(0)$ & $0(0)$ & $0(0)$ \\
\hline
\end{tabular}

Note: The characteristic values of the empty borehole model are inside the brackets, and the characteristic values of the two-ring model are outside the brackets.

Because the grout condensation in the borehole is difficult to control after installation, the mechanical properties of the grout have evident uncertainty. Figure 3 shows the influence of the Young's modulus of grout on the theoretical amplitude spectrum of gauge combinations $F V_{2}$ for borehole tensor strainmeters. The Young's modulus of grout has a large effect on zero-frequency gain and the peak value of $F V_{2}$. The effect of the Poisson's ratio of the grout and the density of the grout on the theoretical amplitude spectrum of gauge combinations $F V_{2}$ for borehole tensor strainmeters are shown in Figures 4 and 5, respectively. The density has no influence on zero-frequency gain but has a large influence on the peak value of $F V_{2}$, and the Poisson's ratio has large influence on both zero-frequency gain and peak value. 


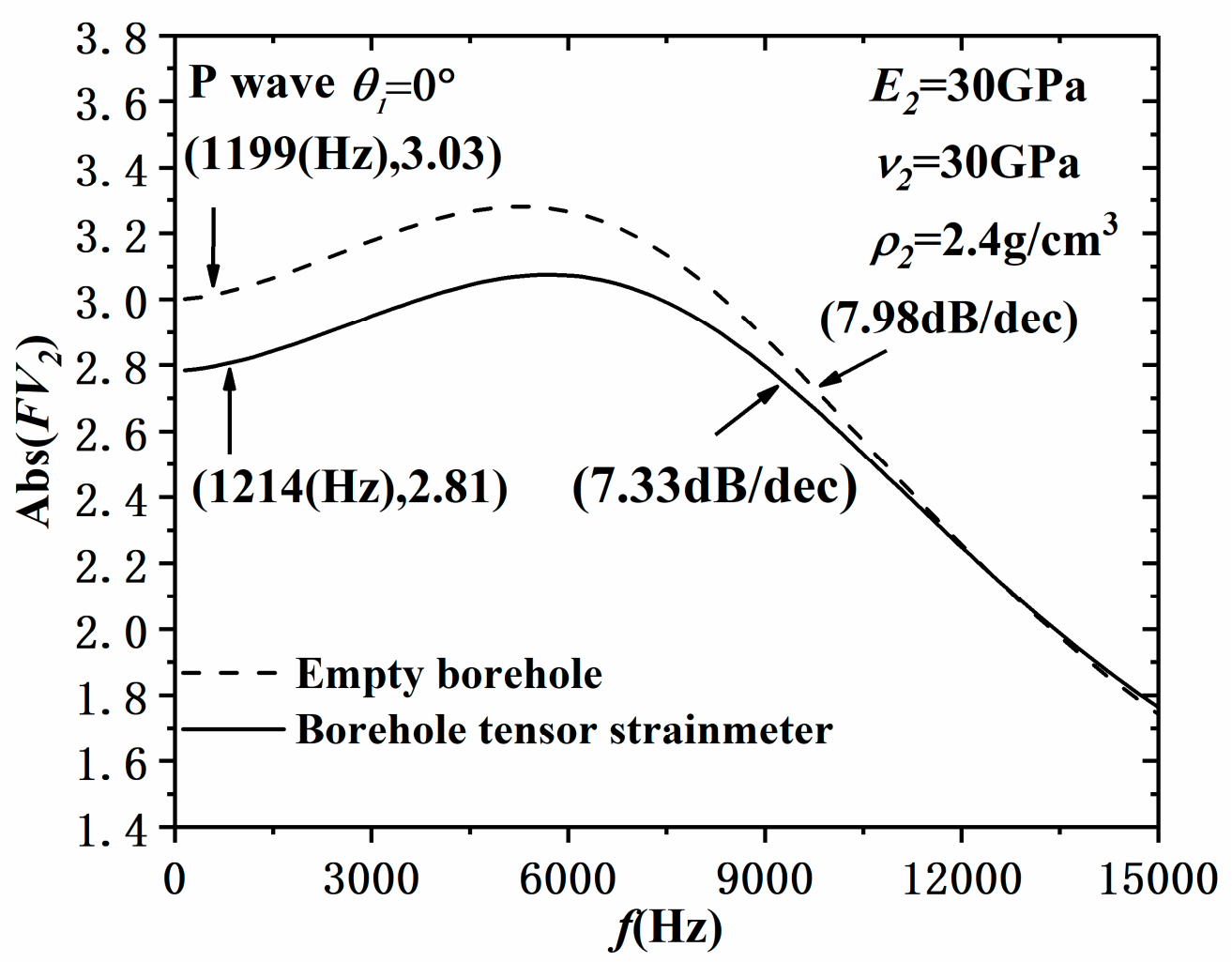

Figure 2. Theoretical amplitude spectrum of gauge combination $F V_{2}$ for the incident $\mathrm{P}$ wave.

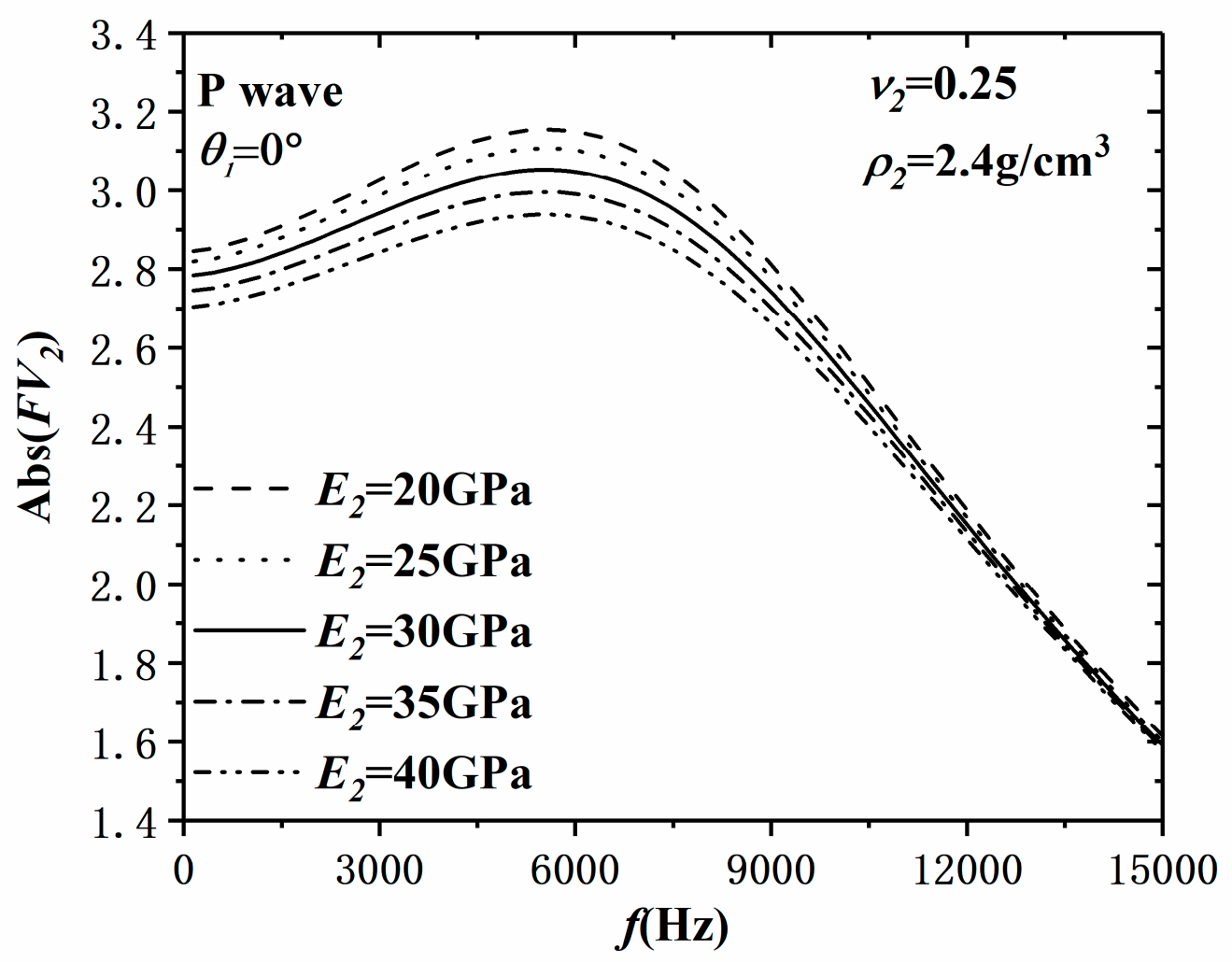

Figure 3. Influence of Young's modulus of the expansive grout on the theoretical amplitude spectrum of gauge combination $F V_{2}$ for the incident $\mathrm{P}$ wave. 


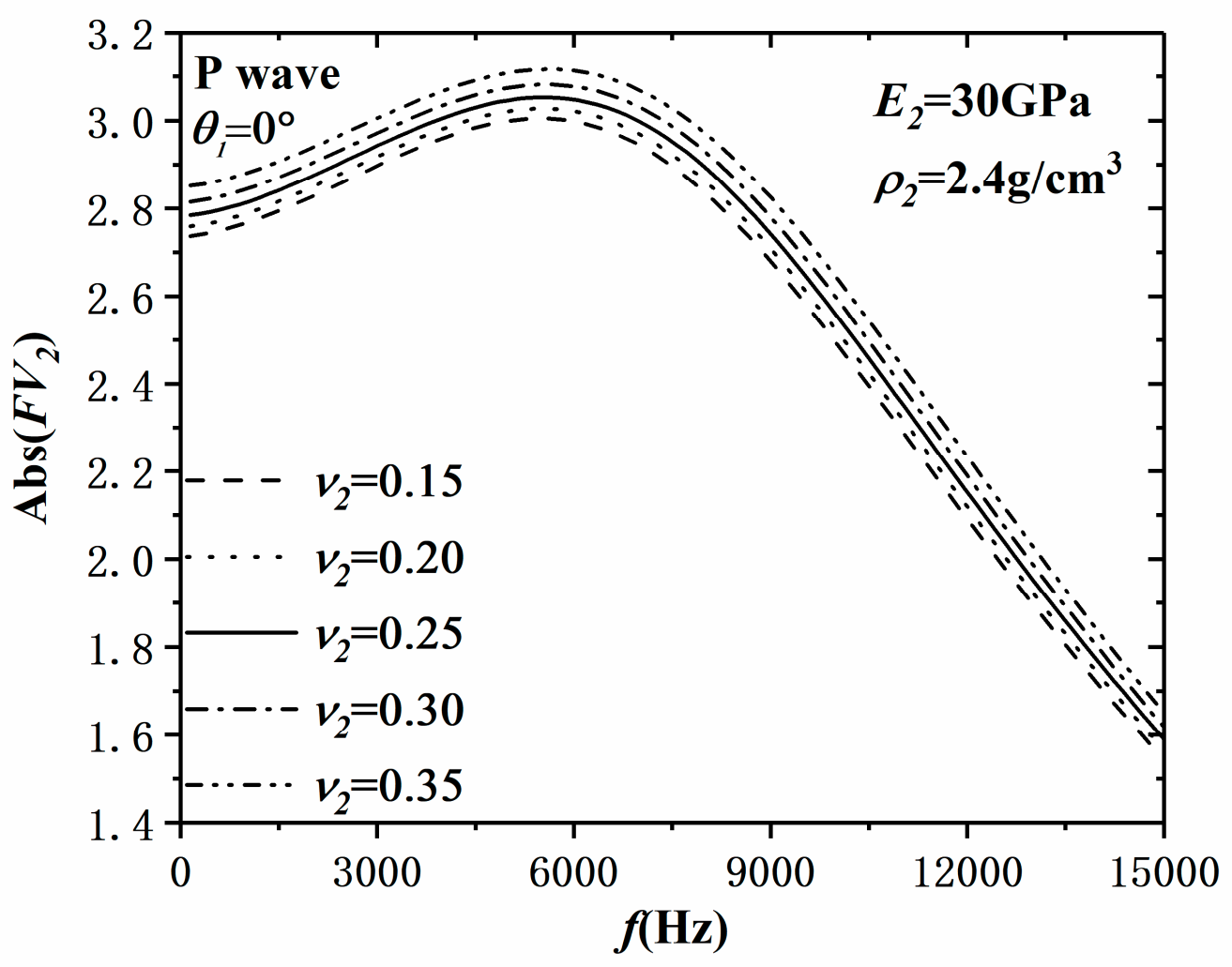

Figure 4. Influence of Poisson's ratio of the expansive grout on the theoretical amplitude spectrum of gauge combination $\mathrm{FV}_{2}$ for the incident $\mathrm{P}$ wave.

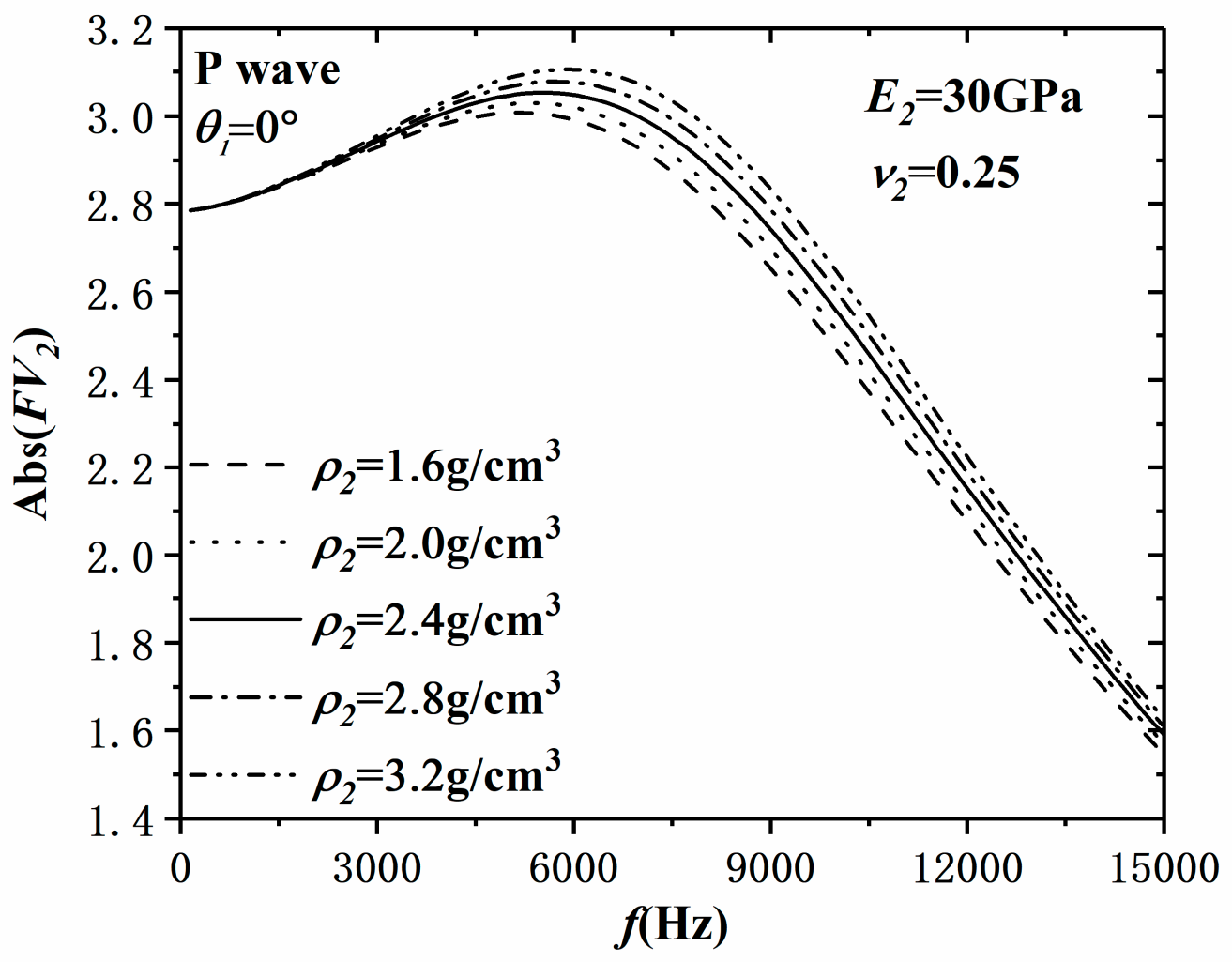

Figure 5. Influence of the expansive grout density on theoretical amplitude spectrum of gauge combination $\mathrm{FV}_{2}$ for the incident $\mathrm{P}$ wave. 
In order to study the influence of the mechanical parameters of the expansive grout on gauge combinations, the effect of the Young's modulus, the Poisson's ratio and the density of the expansive grout on the characteristic values of theoretical frequency responses are listed in Tables 2-4, respectively. It can be seen in Table 2 that as the Young's modulus of the expansive grout increases, the zero-frequency gain, peak value and corresponding frequency of $F V_{2}, F V_{4}$, and $T V$, reflecting the areal strain, decrease slightly. Similarly, the zero-frequency gain and peak values of $F S$ and TS decrease slightly, but the corresponding frequency of the peak value of TS increases. From Table 3, we can see that the Poisson's ratio in the expansive grout makes the zero-frequency gain, peak value and corresponding frequency of $F V_{2}, F V_{4}$ and $T V$ increase, but makes the zero-frequency gain, peak value and corresponding frequency of FS decrease slightly, as the Poisson's ratio in the expansive grout increases. The Poisson's ratio makes the same changes on TS as FS, with the corresponding frequency of peak value. Table 4 shows that the density of the expansive grout makes the peak value and the corresponding frequency of all gauge combinations increase slightly, but has almost no influence on zero-frequency gain.

Table 2. Influence of Young's modulus of the expansive grout on the theoretical amplitude spectrum of gauge combinations $F V_{2}, F V_{4}, F S, T V$ and $T S$ for the incident $\mathrm{P}$ wave.

\begin{tabular}{|c|c|c|c|c|c|}
\hline & \multirow[b]{2}{*}{$\theta_{1}\left({ }^{\circ}\right)$} & \multicolumn{4}{|c|}{$E_{2}=30 \mathrm{GPa}, v_{2}=0.25, \rho_{2}=2.4 \mathrm{~g} / \mathrm{cm}^{3}$} \\
\hline & & $\begin{array}{c}\text { Zero } \\
\text { Frequency Gain }\end{array}$ & $\begin{array}{c}\text { Peak Value } \\
\left(E_{2}-\right) E_{2}\left(E_{2}+\right)\end{array}$ & $\begin{array}{l}f \text { for Peak Value } \\
\left(E_{2}-\right) E_{2}\left(E_{2}+\right)\end{array}$ & $\begin{array}{l}\operatorname{abs}(\max ) \\
E_{2}-\left(E_{2}+\right)\end{array}$ \\
\hline \multirow{7}{*}{$F V_{2}$} & 0 & $(2.85) 2.78(2.70)$ & $(3.15) 3.05(2.94)$ & $(5571) 5543$ (5529) & $0.102(0.115)$ \\
\hline & 15 & $(2.85) 2.78(2.70)$ & (3.16) $3.06(2.95)$ & (5622) 5598 (5590) & $0.103(0.115)$ \\
\hline & 30 & $(2.85) 2.78(2.70)$ & $(3.18) 3.08(2.96)$ & (5724) 5709 (5712) & $0.104(0.116)$ \\
\hline & 45 & $(2.85) 2.78(2.70)$ & (3.19) $3.09(2.97)$ & (5776) 5765 (5774) & $0.104(0.116)$ \\
\hline & 60 & (2.85) $2.78(2.70)$ & (3.18) $3.08(2.96)$ & (5274) 5709 (5712) & $0.104(0.116)$ \\
\hline & 75 & $(2.85) 2.78(2.70)$ & (3.16) $3.06(2.95)$ & (5622) $5598(5590)$ & $0.103(0.115)$ \\
\hline & 90 & (2.85) $2.78(2.70)$ & (3.15) 3.05 (2.94) & (5571) 5543 (5529) & $0.102(0.115)$ \\
\hline \multirow{7}{*}{$F S$} & 0 & $(3.00) 2.90(2.83)$ & $(3.37) 3.23(3.13)$ & $(3823) 3855$ (3897) & $0.137(0.096)$ \\
\hline & 15 & (2.60) $2.51(2.45)$ & (2.92) $2.80(2.71)$ & (3823) 3855 (3897) & $0.119(0.084)$ \\
\hline & 30 & $(1.50) 1.45(1.41)$ & (1.68) 1.62 (1.57) & (3823) $3855(3896)$ & $0.068(0.048)$ \\
\hline & 45 & (0) $0(0)$ & (0) $0(0)$ & (0) $0(0)$ & (0) $0(0)$ \\
\hline & 60 & $(1.50) 1.45(1.41)$ & (1.68) $1.62(1.57)$ & (3823) 3855 (3897) & $0.068(0.048)$ \\
\hline & 75 & (2.60) $2.51(2.45)$ & (2.92) $2.80(2.71)$ & (3823) 3855 (3897) & $0.119(0.084)$ \\
\hline & 90 & $(3.00) 2.90(2.83)$ & (3.17) 3.23 (3.13) & (3823) 3855 (3897) & $0.137(0.096)$ \\
\hline \multirow{7}{*}{$F V_{4}$} & 0 & $(2.85) 2.78(2.70)$ & (3.17) 3.07 (2.95) & $(5673) 5654$ (5651) & $0.103(0.115)$ \\
\hline & 15 & $(2.85) 278(2.70)$ & (3.17) 3.07 (2.95) & (5673) 5654 (5651) & $0.103(0.115)$ \\
\hline & 30 & (2.85) 2. $78(2.70)$ & (3.17) 3.07 (2.95) & (5673) 5654 (5651) & $0.103(0.115)$ \\
\hline & 45 & $(2.85) 2.78(2.70)$ & (3.17) 3.07 (2.95) & (5673) $5654(5651)$ & $0.103(0.115)$ \\
\hline & 60 & $(2.85) 2.78(2.70)$ & (3.17) 3.07 (2.95) & (5673) 5654 (5651) & $0.103(0.115)$ \\
\hline & 75 & (2.85) 2. $78(2.70)$ & (3.17) 3.07 (2.95) & (5673) 5654 (5651) & $0.103(0.115)$ \\
\hline & 90 & (2.85) 2. 78 (2.70) & (3.17) 3.07 (2.95) & (5673) 5654 (5651) & $0.103(0.115)$ \\
\hline \multirow{7}{*}{$T V$} & 0 & $(4.27) 4.18(4.18)$ & $(4.76) 4.60(4.43)$ & $(5673) 5654$ (5651) & $0.155(0.173)$ \\
\hline & 15 & $(4.27) 4.18$ (4.18) & $(4.76) 4.60(4.43)$ & (5673) 5654 (5651) & $0.155(0.173)$ \\
\hline & 30 & $(4.27) 4.18(4.06)$ & $(4.76) 4.60(4.43)$ & (5673) 5654 (5651) & $0.155(0.173)$ \\
\hline & 45 & $(4.27) 4.18(4.06)$ & $(4.76) 4.60(4.43)$ & (5673) 5654 (5651) & $0.155(0.173)$ \\
\hline & 60 & $(4.27) 4.18$ (4.06) & (4.76) $4.60(4.43)$ & (5673) 5654 (5651) & $0.155(0.173)$ \\
\hline & 75 & $(4.27) 4.18(4.06)$ & $(4.76) 4.60(4.43)$ & (5673) 5654 (5651) & $0.155(0.173)$ \\
\hline & 90 & $(4.27) 4.18(4.06)$ & $(4.76) 4.60(4.43)$ & (5673) 5654 (5651) & $0.155(0.173)$ \\
\hline \multirow{7}{*}{ TS } & 0 & (0) $0(0)$ & (0) $0(0)$ & (0) $0(0)$ & (0) $0(0)$ \\
\hline & 15 & $(1.30) 1.26(1.22)$ & (1.46) $1.40(1.36)$ & (3870) $3905(3950)$ & $0.060(0.042)$ \\
\hline & 30 & $(2.25) 2.17(2.12)$ & (2.53) $2.43(2.36)$ & (3850) 3884 (3927) & $0.103(0.073)$ \\
\hline & 45 & (2.60) $2.51(2.45)$ & (2.92) $2.80(2.71)$ & (3823) 3855 (3897) & $0.119(0.084)$ \\
\hline & 60 & $(2.25) 2.17(2.12)$ & (2.52) $2.43(2.35)$ & (3796) 3826 (3866) & $0.102(0.072)$ \\
\hline & 75 & (1.30) 1.25 (1.22) & (1.45) 1.40 (1.35) & (3777) 3806 (3844) & $0.059(0.042)$ \\
\hline & 90 & (0) $0(0)$ & (0) $0(0)$ & (0) $0(0)$ & (0) $0(0)$ \\
\hline
\end{tabular}

Note: $\left(E_{2}-\right) E_{2}\left(E_{2}+\right)$ refers to $(20 \mathrm{GPa}) 30 \mathrm{GPa}(40 \mathrm{GPa})$, respectively. Abs (max) is the absolute maximum of the difference between $\left(E_{2}-\right)$ and $E_{2}$, and between $E_{2}$ and $\left(E_{2}+\right)$, respectively. 
Table 3. Influence of Poisson's ratio of the expansive grout on the theoretical amplitude spectrum of gauge combinations $F V_{2}, F V_{4}, F S, T V$ and $T S$ for the incident $\mathrm{P}$ wave.

\begin{tabular}{|c|c|c|c|c|c|}
\hline & \multirow[b]{2}{*}{$\theta_{1}\left({ }^{\circ}\right)$} & \multicolumn{4}{|c|}{$E_{2}=30 \mathrm{GPa}, v_{2}=0.25, \rho_{2}=2.4 \mathrm{~g} / \mathrm{cm}^{3}$} \\
\hline & & $\begin{array}{c}\text { Zero } \\
\text { Frequency Gain }\end{array}$ & $\begin{array}{l}\text { Peak Value } \\
\left(v_{2}-\right) v_{2}\left(v_{2}+\right)\end{array}$ & $\begin{array}{l}f \text { for Peak Value } \\
\left(v_{2}\right) v_{2}\left(v_{2}+\right)\end{array}$ & $\begin{array}{c}\operatorname{abs}(\max ) \\
v_{2}-\left(v_{2}+\right)\end{array}$ \\
\hline \multirow{7}{*}{$F V_{2}$} & 0 & $(2.74) 2.78(2.85)$ & $(3.00) 3.05(2.94)$ & (5484) $5543(5619)$ & $0.064(0.087)$ \\
\hline & 15 & $(2.74) 2.78(2.85)$ & $(3.01) 3.06(2.95)$ & (5537) 5598 (5678) & $0.064(0.087)$ \\
\hline & 30 & (2.74) $2.78(2.85)$ & (3.03) $3.08(2.96)$ & (5645) 5709 (5794) & $0.064(0.087)$ \\
\hline & 45 & (2.74) $2.78(2.85)$ & (3.03) 3.09 (2.97) & (5699) 5765 (5853) & $0.064(0.087)$ \\
\hline & 60 & (2.74) $2.78(2.85)$ & (3.03) 3.08 (2.96) & (5645) 5709 (5794) & $0.064(0.087)$ \\
\hline & 75 & $(2.74) 2.78(2.85)$ & $(3.01) 3.06(2.95)$ & (5537) 5598 (5678) & $0.064(0.087)$ \\
\hline & 90 & $(2.74) 2.78(2.85)$ & $(3.00) 3.05(2.94)$ & (5484) 5543 (5619) & $0.064(0.087)$ \\
\hline \multirow{7}{*}{ FS } & 0 & $(2.96) 2.90(2.81)$ & $(3.30) 3.23(3.13)$ & (3882) 3855 (3818) & $0.075(0.106)$ \\
\hline & 15 & $(2.56) 2.51(2.44)$ & (2.86) $2.80(2.71)$ & (3882) 3855 (3817) & $0.065(0.091)$ \\
\hline & 30 & (1.48) 1.45 (1.41) & (1.65) 1.62(1.57) & (3881) 3855 (3818) & $0.038(0.053)$ \\
\hline & 45 & (0) $0(0)$ & (0) $0(0)$ & (0) $0(0)$ & (0) $0(0)$ \\
\hline & 60 & (1.48) 1.45 (1.41) & (1.65) $1.62(1.57)$ & (3882) 3855 (3818) & $0.038(0.053)$ \\
\hline & 75 & (2.56) $2.51(2.44)$ & $(2.86) 2.80(2.71)$ & (3881) 3855 (3818) & $0.065(0.091)$ \\
\hline & 90 & $(2.96) 2.90(2.81)$ & $(3.30) 3.23$ (3.13) & (3882) 3855 (3818) & $0.075(0.106)$ \\
\hline \multirow{7}{*}{$F V_{4}$} & 0 & (2.74) 2.78 (2.85) & (3.02) 3.07 (2.95) & (5591) 5654 (5736) & $0.064(0.087)$ \\
\hline & 15 & (2.74) 2.78 (2.85) & (3.02) 3.07 (2.95) & (5591) 5654 (5736) & $0.064(0.087)$ \\
\hline & 30 & (2.74) $2.78(2.85)$ & (3.02) 3.07 (2.95) & (5591) 5654 (5736) & $0.064(0.087)$ \\
\hline & 45 & (2.74) $2.78(2.85)$ & (3.02) 3.07 (2.95) & (5591) 5654 (5736) & $0.064(0.087)$ \\
\hline & 60 & (2.74) 2.78 (2.85) & (3.02) 3.07 (2.95) & (5591) 5654 (5736) & $0.064(0.087)$ \\
\hline & 75 & (2.74) 2.78 (2.85) & (3.02) 3.07 (2.95) & (5591) 5654 (5736) & $0.064(0.087)$ \\
\hline & 90 & $(2.74) 2.78$ (2.85) & $(3.02) 3.07$ (2.95) & (5591) 5654 (5736) & $0.064(0.087)$ \\
\hline \multirow{7}{*}{$T V$} & 0 & (4.11) 4.18 (4.28) & $(4.53) 4.60(4.43)$ & (5591) 5654 (5736) & $0.096(0.130)$ \\
\hline & 15 & (4.11) 4.18 (4.28) & $(4.53) 4.60(4.43)$ & (5591) 5654 (5736) & $0.096(0.130)$ \\
\hline & 30 & (4.11) 4.18 (4.28) & $(4.53) 4.60(4.43)$ & (5591) 5654 (5736) & $0.096(0.130)$ \\
\hline & 45 & (4.11) 4.18 (4.28) & $(4.53) 4.60(4.43)$ & (5591) 5654 (5736) & $0.096(0.130)$ \\
\hline & 60 & (4.11) 4.18 (4.28) & $(4.53) 4.60(4.43)$ & (5591) 5654 (5736) & $0.096(0.130)$ \\
\hline & 75 & (4.11) 4.18 (4.28) & $(4.53) 4.60(4.43)$ & (5591) 5654 (5736) & $0.096(0.130))$ \\
\hline & 90 & (4.11) 4.18 (4.28) & $(4.53) 4.60(4.43)$ & (5591) 5654 (5736) & $0.096(0.130)$ \\
\hline \multirow{7}{*}{ TS } & 0 & $(0) 0(0)$ & (0) $0(0)$ & (0) $0(0)$ & (0) $0(0)$ \\
\hline & 15 & (1.28) $1.26(1.22)$ & (1.44) $1.40(1.36)$ & (3930) 3905 (3869) & $0.033(0.046)$ \\
\hline & 30 & (2.22) $2.17(2.11)$ & $(2.48) 2.43(2.36)$ & (3910) 3884 (3848) & $0.057(0.079)$ \\
\hline & 45 & (2.56) $2.51(2.44)$ & $(2.86) 2.80(2.71)$ & (3882) 3855 (3817) & $0.065(0.091)$ \\
\hline & 60 & $(2.22) 2.17(2.11)$ & $(2.47) 2.43(2.35)$ & (3854) 3826 (3848) & $0.056(0.079)$ \\
\hline & 75 & (1.28) 1.25 (1.22) & (1.43) 1.40 (1.35) & (3833) 3806 (3869) & $0.033(0.046)$ \\
\hline & 90 & (0) $0(0)$ & (0) $0(0)$ & (0) $0(0)$ & $(0) 0(0)$ \\
\hline
\end{tabular}

Note: $\left(v_{2}-\right) v_{2}\left(v_{2}+\right)$ refers to (0.15) $0.25(0.35)$, respectively. Abs (max) is the absolute maximum of the difference between $\left(v_{2}-\right)$ and $v_{2}$, and between $v_{2}$ and $\left(v_{2}+\right)$, respectively.

\subsection{Incident $S$ Wave}

Here, only FS and TS reflecting shear strain are discussed because $F V_{2}, F V_{4}$ and $T V$ reflecting areal strain are zero for the incident $S$ wave.

Figure 6 shows the comparison of amplitude results of the two-ring model and the empty model for incident $S$ wave. It can be seen that the frequency response characteristics of the incident $S$ wave are similar to that of the incident $\mathrm{P}$ wave. The existence of the grout causes the decrease of the peak value and the increase of the corresponding frequency of peak value. 
Table 4. Influence of the expansive grout density on theoretical amplitude spectrum of gauge combinations $F V_{2}, F V_{4}, F S, T V$ and $T S$ for the incident $P$ wave.

\begin{tabular}{|c|c|c|c|c|c|}
\hline & $\theta_{1}\left(^{\circ}\right)$ & $\begin{array}{c}\text { Zero } \\
\text { Frequency Gain }\end{array}$ & $\begin{array}{c}2=30 \mathrm{GPa}, v_{2}= \\
\text { Peak Value } \\
\left(\rho_{2}-\right) \rho_{2}\left(\rho_{2}+\right)\end{array}$ & $\begin{array}{c}\rho_{2}=2.4 \mathrm{~g} / \mathrm{cm}^{3} \\
f \text { for Peak Value } \\
\left(\rho_{2^{-}}\right) \rho_{2}\left(\rho_{2}+\right)\end{array}$ & $\begin{array}{l}\operatorname{abs}(\max ) \\
\rho_{2}-\left(\rho_{2}+\right)\end{array}$ \\
\hline \multirow{7}{*}{$F V_{2}$} & 0 & (2.78) $2.78(2.78)$ & (3.01) 3.05 (3.11) & (5174) 5543 (5906) & $0.089(0.092)$ \\
\hline & 15 & (2.78) 2.78 (2.78) & (3.01) 3.06 (3.11) & (5230) 5598 (5959) & $0.089(0.092)$ \\
\hline & 30 & (2.78) $2.78(2.78)$ & (3.03) 3.08 (3.13) & (5342) 5709 (6067) & $0.089(0.092)$ \\
\hline & 45 & (2.78) 2.78 (2.78) & (3.03) 3.09 (3.14) & (5399) 5765 (6121) & $0.089(0.092)$ \\
\hline & 60 & (2.78) $2.78(2.78)$ & (3.03) $3.08(3.13)$ & (5342) 5709 (6067) & $0.089(0.092)$ \\
\hline & 75 & (2.78) 2.78 (2.78) & (3.01) 3.06 (3.11) & (5230) 5598 (5959) & $0.089(0.092)$ \\
\hline & 90 & (2.78) 2.78 (2.78) & (3.01) 3.05 (3.11) & (5174) 5543 (5906) & $0.089(0.092)$ \\
\hline \multirow{7}{*}{$F S$} & 0 & (2.90) $2.90(2.90)$ & (3.19) 3.23 (3.28) & $(3659) 3855$ (4046) & $0.079(0.081)$ \\
\hline & 15 & (2.51) $2.51(2.51)$ & (2.76) $2.80(2.84)$ & (3659) 3855 (4046) & $0.069(0.070)$ \\
\hline & 30 & (1.46) 1.45 (1.45) & (1.59) 1.62 (1.64) & (3659) 3855 (4046) & $0.040(0.041)$ \\
\hline & 45 & (0) $0(0)$ & (0) $0(0)$ & (0) $0(0)$ & (0) $0(0)$ \\
\hline & 60 & (1.44) 1.45 (1.45) & (1.59) $1.62(1.64)$ & (3659) 3855 (4046) & $0.040(0.041)$ \\
\hline & 75 & $(2.51) 2.51(2.51)$ & (2.76) $2.80(2.84)$ & (3659) 3855 (4046) & $0.069(0.070)$ \\
\hline & 90 & (2.90) $2.90(2.90)$ & (3.19) 3.23 (3.28) & (3659) 3855 (4046) & $0.079(0.081)$ \\
\hline \multirow{7}{*}{$F V_{4}$} & 0 & (2.78) 2.78 (2.78) & (3.02) 3.07 (3.12) & (5286) 5654 (6013) & $0.089(0.092)$ \\
\hline & 15 & (2.78) $2.78(2.78)$ & (3.02) $3.07(3.12)$ & (5286) 5654 (6013) & $0.089(0.092)$ \\
\hline & 30 & (2.78) 2.78 (2.78) & (3.02) 3.07 (3.12) & (5286) 5654 (6013) & $0.089(0.092)$ \\
\hline & 45 & (2.78) 2.78 (2.78) & (3.02) 3.07 (3.12) & (5286) 5654 (6013) & $0.089(0.092)$ \\
\hline & 60 & (2.78) $2.78(2.78)$ & (3.02) $3.07(3.12)$ & (5286) $5654(6013)$ & $0.089(0.092)$ \\
\hline & 75 & (2.78) 2.78 (2.78) & (3.02) 3.07 (3.12) & (5286) 5654 (6013) & $0.089(0.092)$ \\
\hline & 90 & (2.78) 2.78 (2.78) & (3.02) $3.07(3.12)$ & (5286) 5654 (6013) & $0.089(0.092)$ \\
\hline \multirow{7}{*}{$T V$} & 0 & (4.18) 4.18 (4.18) & $(4.53) 4.60(4.68)$ & (5286) 5654 (6014) & $0.096(0.130)$ \\
\hline & 15 & $(4.18) 4.18$ (4.18) & $(4.53) 4.60(4.68)$ & (5286) 5654 (6013) & $0.096(0.130)$ \\
\hline & 30 & $(4.18) 4.18$ (4.06) & (4.53) 4.60 (4.68) & (5286) 5654 (6013) & $0.096(0.130)$ \\
\hline & 45 & (4.18) 4.18 (4.06) & (4.53) 4.60 (4.68) & (5286) 5654 (6013) & $0.096(0.130)$ \\
\hline & 60 & $(4.18) 4.18$ (4.06) & $(4.53) 4.60$ (4.68) & (5286) 5654 (6014) & $0.096(0.130)$ \\
\hline & 75 & $(4.18) 4.18$ (4.06) & $(4.53) 4.60(4.68)$ & (5286) 5654 (6013) & $0.096(0.130))$ \\
\hline & 90 & (4.18) 4.18 (4.06) & $(4.53) 4.60(4.68)$ & (5286) 5654 (6013) & $0.096(0.130)$ \\
\hline \multirow{7}{*}{$T S$} & 0 & (0) $0(0)$ & (0) $0(0)$ & (0) $0(0)$ & (0) $0(0)$ \\
\hline & 15 & (1.25) $1.26(1.26)$ & (1.38) $1.40(1.43)$ & (3710) 3905 (4094) & $0.034(0.035)$ \\
\hline & 30 & (2.17) 2.17 (2.17) & (2.39) 2.43 (2.47) & (3688) 3884 (4074) & $0.059(0.061)$ \\
\hline & 45 & (2.51) $2.51(2.51)$ & (2.76) $2.80(2.84)$ & (3659) 3855 (4046) & $0.069(0.070)$ \\
\hline & 60 & (2.18) 2.17 (2.17) & (2.38) $2.43(2.46)$ & (3629) 3826 (4019) & $0.060(0.061)$ \\
\hline & 75 & (1.26) 1.25 (1.25) & (1.37) 1.40 (1.42) & (3608) 3806 (3998) & $0.034(0.035)$ \\
\hline & 90 & $(0) 0(0)$ & (0) $0(0)$ & (0) $0(0)$ & $(0) 0(0)$ \\
\hline
\end{tabular}

Note: $\left(\rho_{2^{-}}\right) \rho_{2}\left(\rho_{2}+\right)$ refers to $\left(1.6 \mathrm{~g} / \mathrm{cm}^{3}\right) 2.4 \mathrm{~g} / \mathrm{cm}^{3}\left(3.2 \mathrm{~g} / \mathrm{cm}^{3}\right)$, respectively. Abs (max) is the absolute maximum of the difference between $\left(\rho_{2}-\right)$ and $\rho_{2}$, and between $\rho_{2}$ and $\left(\rho_{2}+\right)$, respectively.

Table 5 shows the characteristic parameters for the incident $S$ wave. As can be seen from the table, the peak value, attenuation rate, $1 \%$ bandwidth and amplitude of the two-ring are smaller than in the empty borehole model, while the corresponding frequency of peak value and the corresponding frequency of $1 \%$ bandwidth are larger than in the empty borehole model. It shows that the expansive grout will cause the peak value to decrease, and cause the overall change trend to slow down. 


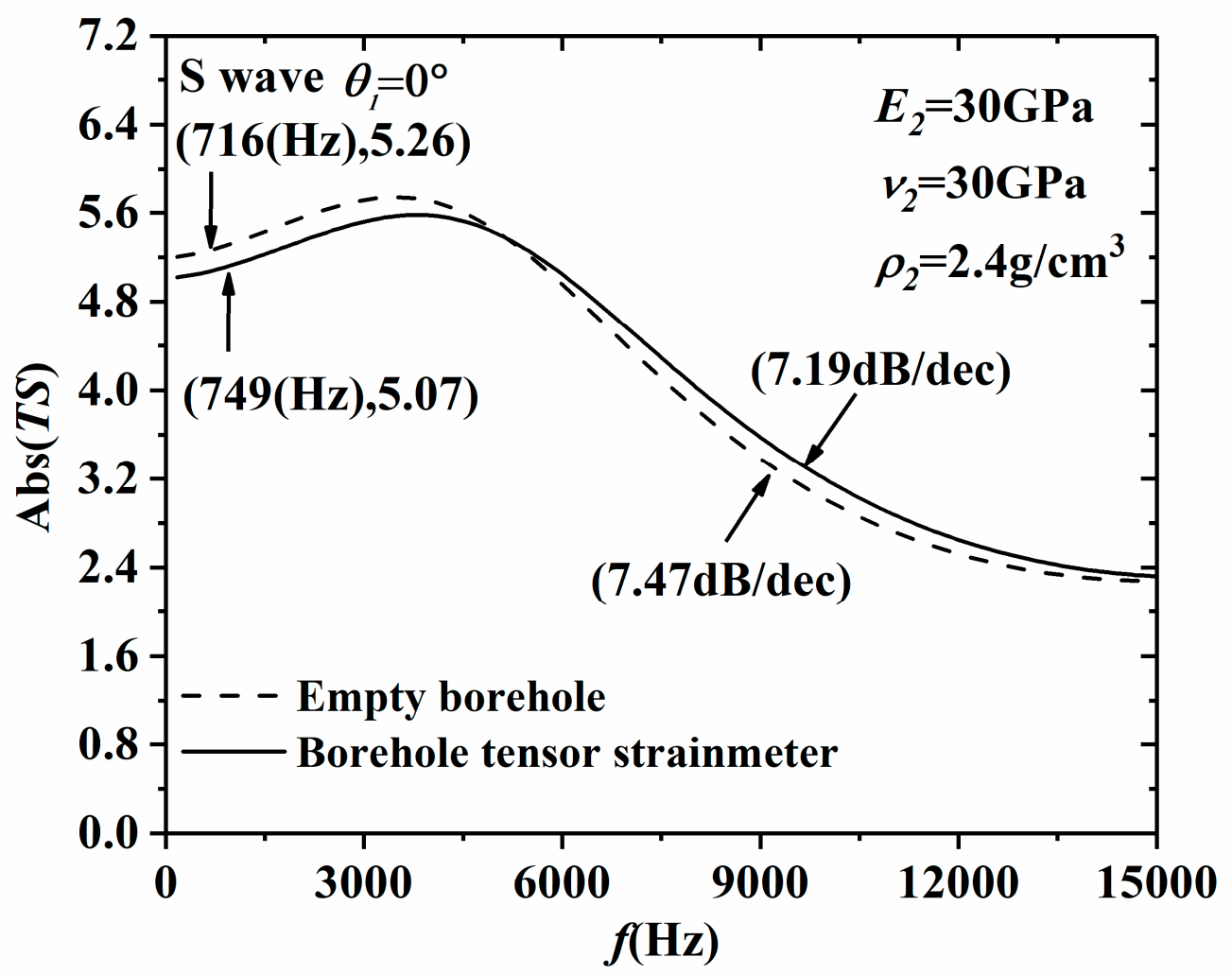

Figure 6. Theoretical amplitude spectrum of gauge combination TS for the incident $S$ wave.

Table 5. Characteristic values for incident $S$ wave amplitude spectrum of $F S$ and TS at different $\theta_{1}$.

\begin{tabular}{|c|c|c|c|c|c|c|c|}
\hline & \multirow{2}{*}{$\theta_{1}\left(^{\circ}\right)$} & \multicolumn{6}{|c|}{$E_{2}=30 \mathrm{GPa}, v_{2}=0.25, \rho_{2}=2.4 \mathrm{~g} / \mathrm{cm}^{3}$} \\
\hline & & $\begin{array}{c}\text { Zero } \\
\text { Frequency Gain }\end{array}$ & $\begin{array}{l}\text { Peak } \\
\text { Value }\end{array}$ & $\begin{array}{l}f \text { for Peak } \\
\text { Value }\end{array}$ & $\begin{array}{l}\text { Roll-off } \\
\text { dB/dec }\end{array}$ & $\begin{array}{c}1 \% \\
\text { Bandwidth }\end{array}$ & $\begin{array}{l}f \text { for } 1 \% \\
\text { Bandwidth }\end{array}$ \\
\hline \multirow{7}{*}{ FS } & 0 & $0(0)$ & $0(0)$ & $0(0)$ & $0(0)$ & $0(0)$ & $0(0)$ \\
\hline & 15 & $2.90(3.00)$ & $3.20(3.29)$ & $3718(3400)$ & $7.75(8.26)$ & $2.93(3.03)$ & $748(723)$ \\
\hline & 30 & $5.02(5.20)$ & 5.55 (5.71) & 3718 (3399) & 7.79 (8.28) & $5.07(5.25)$ & 748 (723) \\
\hline & 45 & $5.80(6.00)$ & $6.40(6.59)$ & $3718(3399)$ & $7.81(8.30)$ & $5.86(6.07)$ & $748(723)$ \\
\hline & 60 & $5.02(5.20)$ & $5.55(5.71)$ & $3718(3399)$ & $7.80(8.28)$ & $5.07(5.25)$ & $748(723)$ \\
\hline & 75 & $2.90(3.00)$ & $3.20(3.29)$ & $3718(3400)$ & $7.79(8.26)$ & $2.93(3.03)$ & $747(723)$ \\
\hline & 90 & (0) & $0(0)$ & $0(0)$ & $0(0)$ & $0(0)$ & $0(0)$ \\
\hline \multirow{7}{*}{ TS } & 0 & $5.02(5.20)$ & $5.58(5.74)$ & $3801(3476)$ & $7.19(7.47)$ & $5.07(5.26)$ & $749(716)$ \\
\hline & 15 & $4.35(4.50)$ & $4.82(4.96)$ & 3766 (3443) & $7.45(7.81)$ & $4.39(4.55)$ & 748 (719) \\
\hline & 30 & $2.51(2.60)$ & $2.76(2.84)$ & 3635 (3323) & $8.42(9.13)$ & $2.54(2.63)$ & 747 (730) \\
\hline & 45 & $0(0)$ & $0(0)$ & $0(0)$ & $0(0)$ & $0(0)$ & $0(0)$ \\
\hline & 60 & $2.51(2.60)$ & $2.79(2.87)$ & $3801(3476)$ & $7.17(7.47)$ & $2.54(2.63)$ & 749 (716) \\
\hline & 75 & $4.35(4.50)$ & $4.79(4.93)$ & 3670 (3355) & $8.14(8.77)$ & $4.39(4.55)$ & 748 (727) \\
\hline & 90 & $5.02(5.20)$ & $5.51(5.67)$ & 3635 (3323) & $8.40(9.13)$ & $5.07(5.25)$ & $747(730)$ \\
\hline
\end{tabular}

Note: the characteristic values of the empty borehole model are inside the brackets, and the characteristic values of the two-ring model are outside the brackets.

Figures 7-9 describe the influence of the Young's modulus, Poisson's ratio and density of the expansive grout on the theoretical amplitude spectrum of gauge combination TS for the incident $S$ wave, respectively. The changes of the Young's modulus and Poisson's ratio cause large changes in the amplitude of $F S$ at small incident wave frequency $f$, while there is almost no change with the different densities of the expansive grout. From Tables 6-8, we see that the influence of the Young's modulus, Poisson's ratio and density of the expansive grout on FS and TS for the incident $S$ wave are the same as that of the incident $\mathrm{P}$ wave, except for the influence of the Poisson's ratio on the corresponding frequency of peak value. 


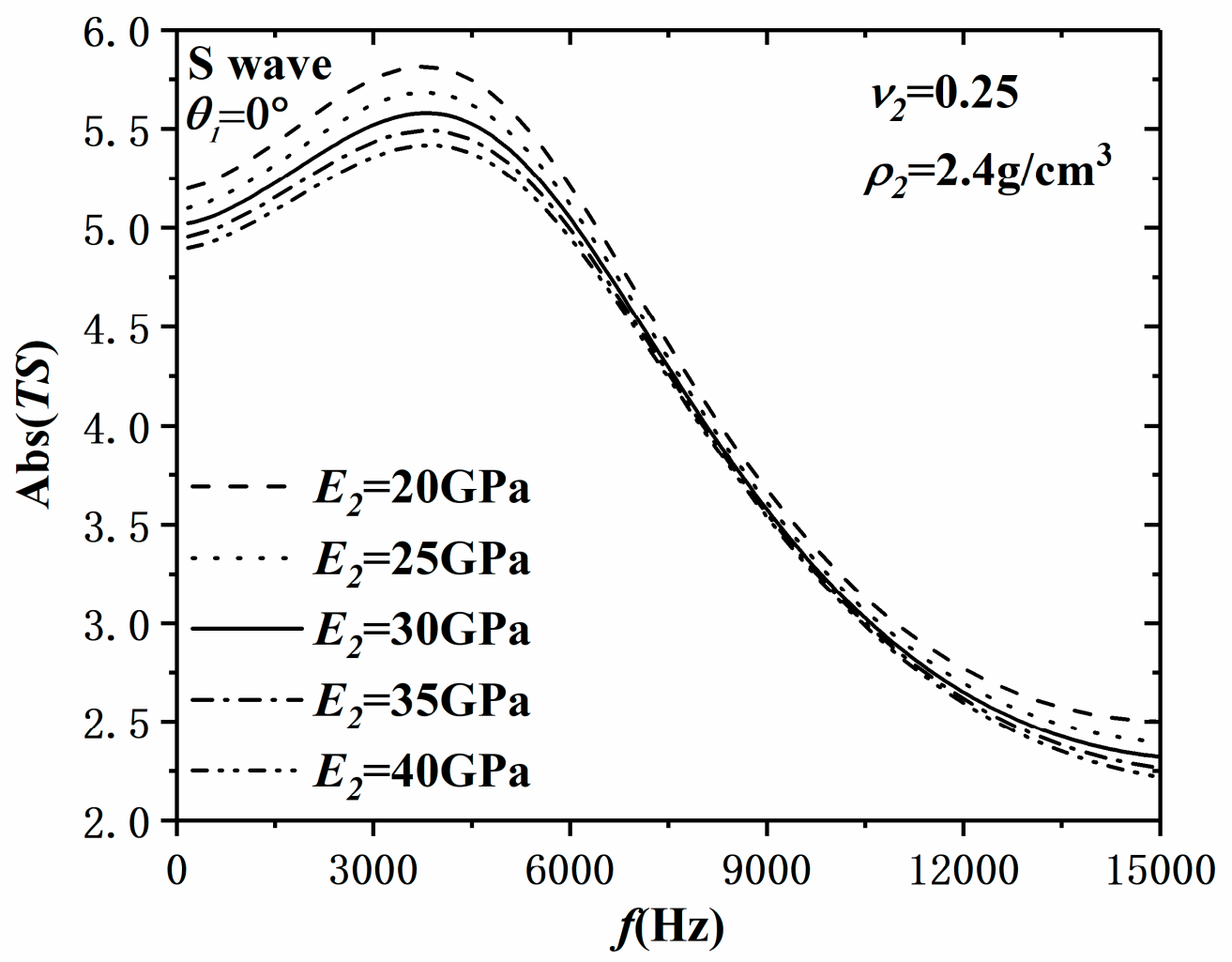

Figure 7. Influence of the Young's modulus of the expansive grout on theoretical amplitude spectrum of gauge combination TS for the incident $S$ wave.

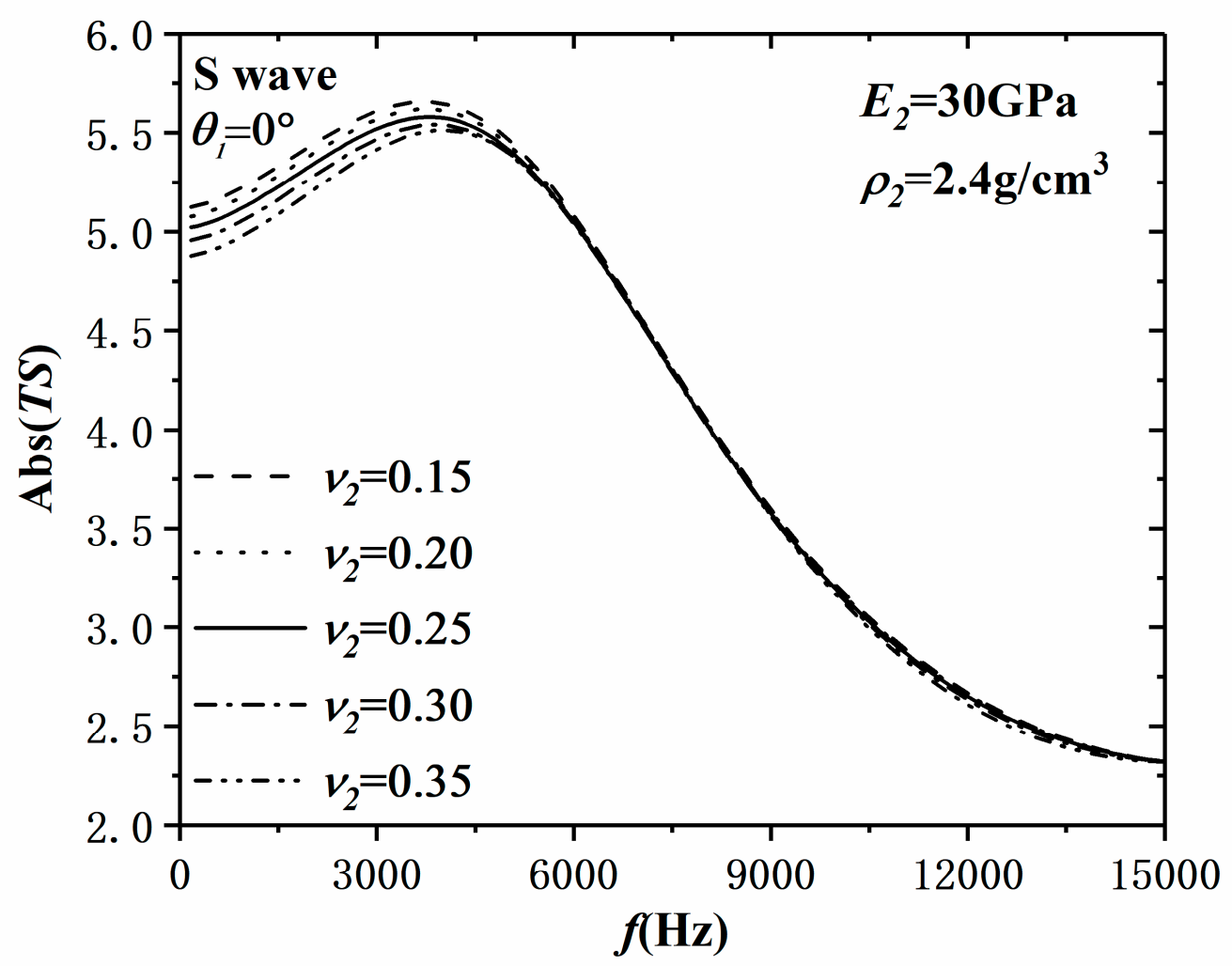

Figure 8. Influence of the Poisson's ratio of the expansive grout on theoretical amplitude spectrum of gauge combination TS for the incident $\mathrm{S}$ wave. 


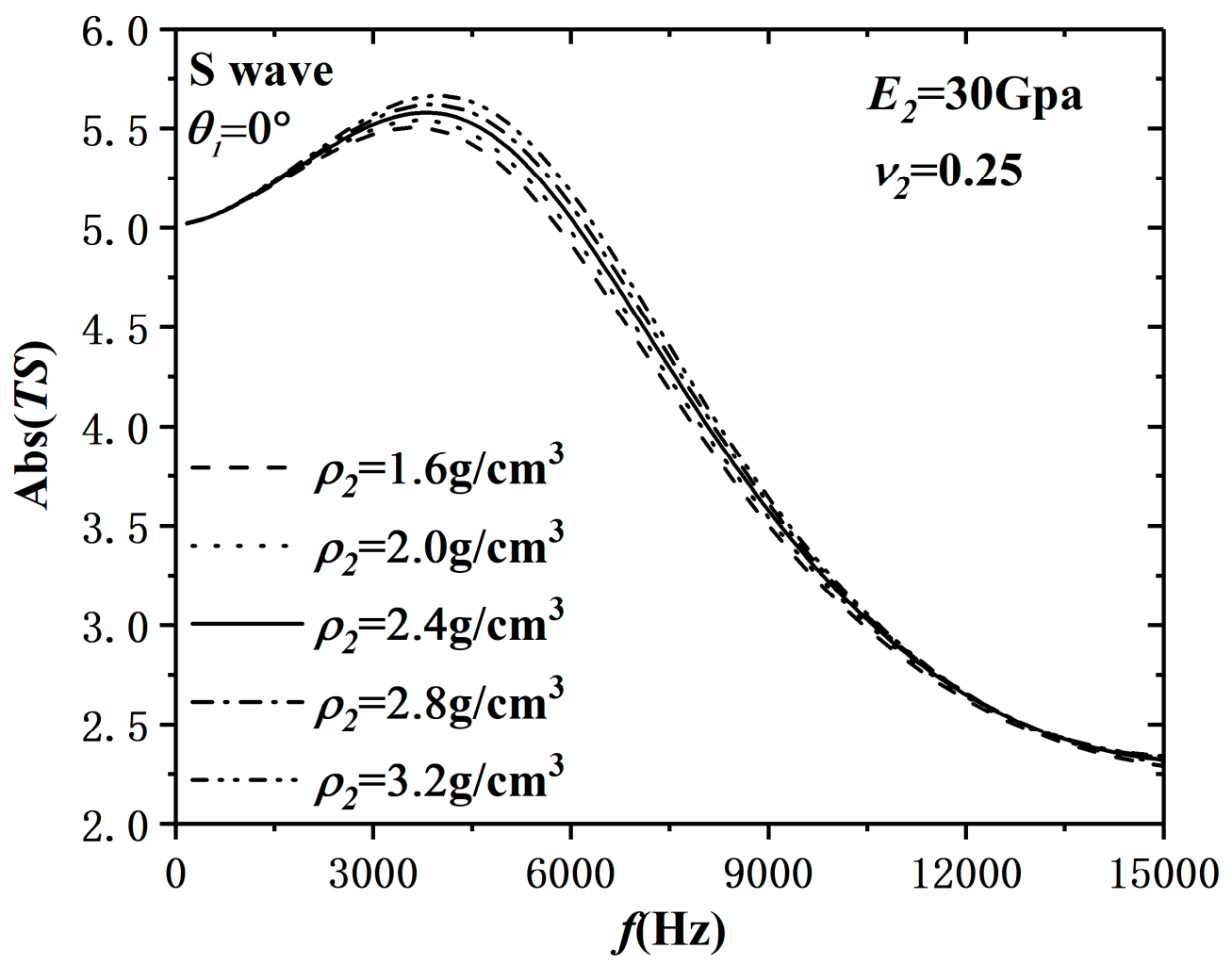

Figure 9. Influence of the expansive grout density on theoretical amplitude spectrum of gauge combination TS for the incident $S$ wave.

Table 6. Influence of the Young's modulus of the expansive grout on theoretical amplitude spectrum of gauge combinations FS and TS for the incident $S$ wave.

\begin{tabular}{|c|c|c|c|c|c|}
\hline & \multirow{3}{*}{$\theta_{1}\left({ }^{\circ}\right)$} & \multicolumn{4}{|c|}{$E_{2}=30 \mathrm{GPa}, v_{2}=0.25, \rho_{2}=2.4 \mathrm{~g} / \mathrm{cm}^{3}$} \\
\hline & & Zero & Peak Value & $f$ for Max & $\operatorname{abs}(\max )$ \\
\hline & & Frequency Gain & $\left(E_{2}-\right) E_{2}\left(E_{2}+\right)$ & $\left(E_{2}-\right) E_{2}\left(E_{2}+\right)$ & $E_{2}-\left(E_{2}+\right)$ \\
\hline \multirow{7}{*}{ FS } & 0 & (0) $0(0)$ & (0) $0(0)$ & (0) $0(0)$ & $0(0)$ \\
\hline & 15 & (3.00) $2.90(2.83)$ & (3.34) $3.20(3.11)$ & (3687) 3718 (3760) & $0.468(0.339)$ \\
\hline & 30 & (5.20) $5.02(4.90)$ & $(5.78) 5.55(5.38)$ & (3687) 3718 (3759) & $0.811(0.586)$ \\
\hline & 45 & $(6.00) 5.80(5.66)$ & $(6.67) 6.40(6.22)$ & (3687) 3718 (3759) & $0.963(0.677)$ \\
\hline & 60 & $(5.20) 5.02(4.90)$ & (5.78) $5.55(5.38)$ & (3687) 3718 (3759) & $0.811(0.568)$ \\
\hline & 75 & (3.00) $2.90(2.83)$ & (3.34) $3.20(3.11)$ & (3687) 3718 (3759) & $0.468(0.339)$ \\
\hline & 90 & (0) $0(0)$ & (0) $0(0)$ & (0) $0(0)$ & $0(0)$ \\
\hline \multirow{7}{*}{ TS } & 0 & (5.20) $5.02(4.90)$ & (5.81) $5.58(5.42)$ & (3765) 3801 (3849) & $0.811(0.586)$ \\
\hline & 15 & $(4.50) 4.35$ (4.24) & (5.02) $4.82(4.68)$ & (3731) 3766 (3811) & $0.702(0.508)$ \\
\hline & 30 & $(2.60) 2.51(2.45)$ & (2.87) $2.76(2.68)$ & $(3609) 3635$ (3670) & $0.405(0.293)$ \\
\hline & 45 & (0) $0(0)$ & (0) $0(0)$ & (0) $0(0)$ & $0(0)$ \\
\hline & 60 & $(2.60) 2.51(2.45)$ & $(2.91) 2.79(2.71)$ & (3765) 3801 (3849) & $0.405(0.293)$ \\
\hline & 75 & $(4.50) 4.35(4.24)$ & (4.99) 4.79 (4.65) & (3642) 3670 (3708) & $0.702(0.508)$ \\
\hline & 90 & $(5.20) 5.02(4.90)$ & (5.74) 5.51 (5.35) & (3610) 3635 (3670) & $0.811(0.586)$ \\
\hline
\end{tabular}

Note: $\left(E_{2}-\right) E_{2}\left(E_{2}+\right)$ refers to $(20 \mathrm{GPa}) 30 \mathrm{GPa}(40 \mathrm{GPa})$, respectively. Abs (max) is the absolute maximum of the difference between $\left(E_{2^{-}}\right)$and $E_{2}$, and between $E_{2}$ and $\left(E_{2}+\right)$, respectively. 
Table 7. Influence of the Poisson's ratio of the expansive grout on theoretical amplitude spectrum of gauge combinations FS and TS for the incident $S$ wave.

\begin{tabular}{|c|c|c|c|c|c|}
\hline & \multirow[b]{2}{*}{$\theta_{1}\left({ }^{\circ}\right)$} & \multicolumn{4}{|c|}{$E_{2}=30 \mathrm{GPa}, v_{2}=0.25, \rho_{2}=2.4 \mathrm{~g} / \mathrm{cm}^{3}$} \\
\hline & & $\begin{array}{c}\text { Zero } \\
\text { Frequency Gain }\end{array}$ & $\begin{array}{l}\text { Peak Value } \\
\left(v_{2}-\right) v_{2}\left(v_{2}+\right)\end{array}$ & $\begin{array}{c}f \text { for Max } \\
\left(v_{2}-\right) v_{2}\left(v_{2}+\right)\end{array}$ & $\begin{array}{l}\operatorname{abs}(\max ) \\
v_{2}-\left(v_{2}+\right)\end{array}$ \\
\hline \multirow{7}{*}{ FS } & 0 & (0) $0(0)$ & (0) $0(0)$ & (0) $0(0)$ & $0(0)$ \\
\hline & 15 & $(2.96) 2.90(2.82)$ & $(3.25) 3.20(3.16)$ & (3624) 3718 (3938) & $0.192(0.185)$ \\
\hline & 30 & (5.12) $5.02(4.88)$ & (5.62) $5.55(5.48)$ & (3624) 3718 (3937) & $0.332(0.321)$ \\
\hline & 45 & (5.92) $5.80(5.63)$ & $(6.49) 6.40(6.32)$ & (3624) 3718 (3937) & $0.384(0.370)$ \\
\hline & 60 & (5.12) $5.02(4.88)$ & (5.62) $5.55(5.48)$ & (3624) 3718 (3937) & $0.332(0.321)$ \\
\hline & 75 & $(2.96) 2.90(2.82)$ & $(3.25) 3.20(3.16)$ & (3623) 3718 (3937) & $0.192(0.185)$ \\
\hline & 90 & (0) $0(0)$ & (0) $0(0)$ & (0) $0(0)$ & $0(0)$ \\
\hline \multirow{7}{*}{ TS } & 0 & $(5.12) 5.02(4.88)$ & $(5.66) 5.58(5.51)$ & (3707) 3801 (4020) & $0.332(0.321)$ \\
\hline & 15 & $(4.44) 4.35(4.22)$ & $(4.89) 4.82(4.76)$ & (3671) 3766 (3890) & $0.288(0.278)$ \\
\hline & 30 & (2.56) $2.51(2.44)$ & $(2.80) 2.76(2.72)$ & (3542) 3635 (3855) & $0.166(0.160)$ \\
\hline & 45 & (0) $0(0)$ & (0) $0(0)$ & (0) $0(0)$ & $0(0)$ \\
\hline & 60 & $(2.56) 2.51(2.44)$ & $(2.83) 2.79$ (2.76) & (3707) 3801 (4020) & $0.166(0.160)$ \\
\hline & 75 & $(4.44) 4.35$ (4.22) & $(4.85) 4.79$ (4.72) & $(3576) 3670$ (3890) & $0.288(0.278)$ \\
\hline & 90 & (5.12) $5.02(4.88)$ & (5.59) $5.51(5.44)$ & (3541) 3635 (3855) & $0.332(0.321)$ \\
\hline
\end{tabular}

Note: $\left(v_{2}-\right) v_{2}\left(v_{2}+\right)$ refers to $(0.15) 0.25(0.35)$, respectively. Abs (max) is the absolute maximum of the difference between $\left(v_{2}-\right)$ and $v_{2}$, and between $v_{2}$ and $\left(v_{2}+\right)$, respectively.

Table 8. Influence of the expansive grout density on theoretical amplitude spectrum of gauge combinations FS and TS for the incident $S$ wave.

\begin{tabular}{|c|c|c|c|c|c|}
\hline & \multirow{3}{*}{$\theta_{1}\left({ }^{\circ}\right)$} & \multicolumn{4}{|c|}{$E_{2}=30 \mathrm{GPa}, v_{2}=0.25, \rho_{2}=2.4 \mathrm{~g} / \mathrm{cm}^{3}$} \\
\hline & & Zero & Peak Value & $f$ for Max & $\operatorname{abs}(\max )$ \\
\hline & & Frequency Gain & $\left(\rho_{2}^{-}\right) \rho_{2}\left(\rho_{2}+\right)$ & $\left(\rho_{2}^{-}\right) \rho_{2}\left(\rho_{2}+\right)$ & $\rho_{2}-\left(\rho_{2}+\right)$ \\
\hline \multirow{7}{*}{ FS } & 0 & (0) $0(0)$ & (0) $0(0)$ & (0) $0(0)$ & $0(0)$ \\
\hline & 15 & $(2.90) 2.90(2.90)$ & $(3.16) 3.20(3.25)$ & (3526) 3718 (3906) & $0.075(0.077)$ \\
\hline & 30 & (5.02) $5.02(5.02)$ & (5.47) $5.55(5.63)$ & (3526) 3718 (3906) & $0.130(0.134)$ \\
\hline & 45 & $(5.80) 5.80(5.80)$ & $(6.32) 6.40(6.50)$ & (3525) 3718 (3906) & $0.151(0.154)$ \\
\hline & 60 & (5.02) $5.02(5.02)$ & (5.47) 5.55 (5.63) & $(3525) 3718(3906)$ & $0.130(0.134)$ \\
\hline & 75 & $(2.90) 2.90(2.90)$ & $(3.16) 3.20(3.25)$ & (3525) 3718 (3905) & $0.075(0.077)$ \\
\hline & 90 & (0) $0(0)$ & (0) $0(0)$ & (0) $0(0)$ & $0(0)$ \\
\hline \multirow{7}{*}{ TS } & 0 & (5.02) $5.02(5.02)$ & (5.58) 5.58 (5.66) & (3801) 3801 (3986) & $0.130(0.133)$ \\
\hline & 15 & (4.35) 4.35 (4.35) & $(4.82) 4.82(4.89)$ & (3766) 3766 (3952) & $0.113(0.116)$ \\
\hline & 30 & (2.51) $2.51(2.51)$ & $(2.76) 2.76(2.80)$ & $(3635) 3635$ (3826) & $0.065(0.067)$ \\
\hline & 45 & (0) $0(0)$ & (0) $0(0)$ & (0) $0(0)$ & $0(0)$ \\
\hline & 60 & $(2.51) 2.51(2.51)$ & $(2.79) 2.79(2.83)$ & (3801) 3801 (3986) & $0.065(0.067)$ \\
\hline & 75 & $(4.35) 4.35$ (4.35) & $(4.79) 4.79(4.85)$ & (3670) 3670 (3860) & $0.113(0.116)$ \\
\hline & 90 & (5.02) $5.02(5.02)$ & (5.51) $5.51(5.59)$ & $(3635) 3635$ (3826) & $0.131(0.134)$ \\
\hline
\end{tabular}

Note: $\left(\rho_{2}-\right) \rho_{2}\left(\rho_{2}+\right)$ refers to $\left(1.6 \mathrm{~g} / \mathrm{cm}^{3}\right) 2.4 \mathrm{~g} / \mathrm{cm}^{3}\left(3.2 \mathrm{~g} / \mathrm{cm}^{3}\right)$, respectively. Abs (max) is the absolute maximum of the difference between $\left(\rho_{2}-\right)$ and $\rho_{2}$, and between $\rho_{2}$ and $\left(\rho_{2}+\right)$, respectively.

\section{Discussions}

Though the mechanical parameters of the expansive grout have an influence on the characteristic parameters of gauge combinations, the relative difference between the maximum and minimum in the range of mechanical parameters discussed in this paper is still small, according to Tables 2-4 and Tables 6-8. In addressing whether borehole strainmeters can be used for quantitatively measuring seismic strain waves independently from the mechanical parameters of expansive grout, the influence of different modulus on bandwidth is discussed here.

As shown in Figure 10, the $1 \%$ bandwidths of $F V_{2}, F S, F V_{4}$ and $T V$ increase with the increase of $v_{2}$. It can be seen in Table 9 that no matter how the mechanical parameters change in the range discussed in this paper, even if the surrounding rocks are saturated corresponding to higher Poisson ratio, the $1 \%$ 
bandwidth of all gauge combinations for borehole strainmeters is still beyond $200 \mathrm{~Hz}$. This means that it is possible to measure high-frequency microseismic strain waves quantitatively.

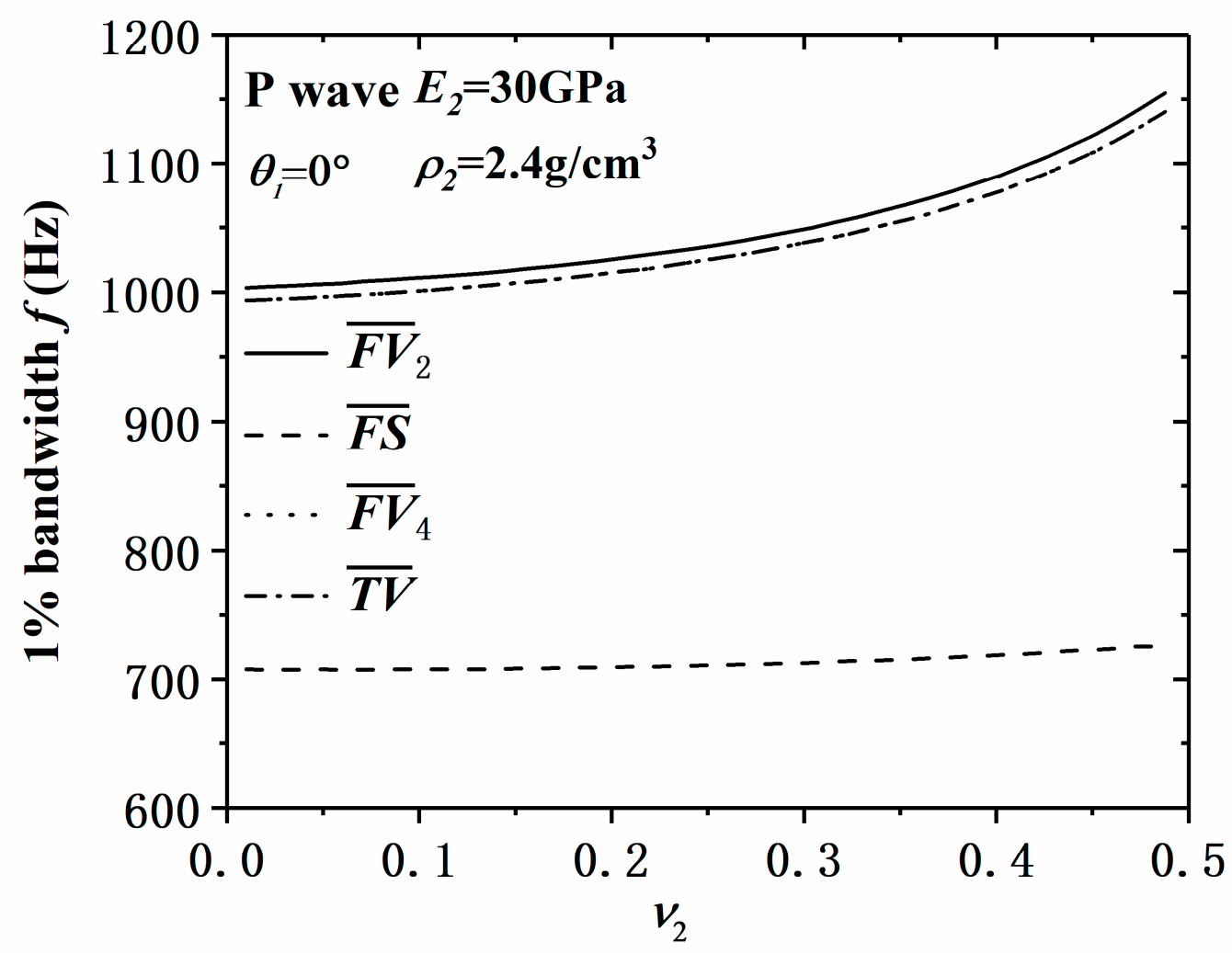

Figure 10. The influence of the Poisson ratio $v_{2}$ of the expansive grout on $1 \%$ bandwidth of $F V_{2}, F V_{4}$, $T V$ and FS for borehole tensor strainmeters for the incident $\mathrm{P}$ wave.

Table 9. $1 \%$ bandwidth of gauge combinations for different mechanical parameters of the expansive grout by incident $\mathrm{P} / \mathrm{S}$ wave.

\begin{tabular}{ccccc}
\hline Wave Types & $\begin{array}{c}\text { Bandwidth of Gauge } \\
\text { Combinations }\end{array}$ & $\begin{array}{c}E_{\mathbf{2}} \\
\mathbf{( 2 0} \mathbf{G P a} \mathbf{4 0} \mathbf{G P a})\end{array}$ & $\begin{array}{c}\boldsymbol{v}_{\mathbf{2}} \\
\mathbf{( 0 . 1 5} \mathbf{0 . 3 5})\end{array}$ & $\begin{array}{c}\boldsymbol{\rho}_{\mathbf{2}} \\
\mathbf{( 1 . 6} \mathbf{~ g / \mathbf { c m } ^ { 3 } \sim 3 . 2} \mathbf{~} / \mathbf{c m}^{\mathbf{3}} \mathbf{)}\end{array}$ \\
\hline \multirow{5}{*}{ P wave } & $1 \%$ bandwidth of $F V_{2}(\mathrm{~Hz})$ & $923 \sim 1029$ & $1019 \sim 1068$ & $796 \sim 912$ \\
& $1 \%$ bandwidth of $F S(\mathrm{~Hz})$ & $619 \sim 649$ & $708 \sim 715$ & $643 \sim 705$ \\
& $1 \%$ bandwidth of $F V_{4}(\mathrm{~Hz})$ & $916 \sim 1018$ & $1008 \sim 1056$ & $797 \sim 907$ \\
& $1 \%$ bandwidth of $T V(\mathrm{~Hz})$ & $916 \sim 1018$ & $1008 \sim 1056$ & $979 \sim 907$ \\
\multirow{2}{*}{ S wave } & $1 \%$ bandwidth of $T S(\mathrm{~Hz})$ & $689 \sim 732$ & $808 \sim 713$ & $641 \sim 705$ \\
\hline
\end{tabular}

\section{Conclusions}

The model of incident elastic $\mathrm{P} / \mathrm{S}$ wave scattering by the two-ring borehole has been presented to investigate the influence of the expansive grout on the theoretical bandwidth of borehole tensor strainmeters. The existence of grout decreases the zero-frequency gains and peak values of $F V_{2}, F V_{4}$, $T V, F S$, and TS, and increases the corresponding $f$ for peak value relative to the empty borehole. Except for the zero-frequency gains of gauge combinations, the theoretical bandwidths of gauge combinations are not influenced by the mechanical properties of the expansive grout compared with the empty borehole, which suggests the quantitative measurability of high-frequency seismic strain waves by borehole tensor strainmeters with a theoretical bandwidth of more than $200 \mathrm{~Hz}$. Furthermore, it provides a theoretical basis for the in situ calibration of borehole tensor strainmeters and the further study of seismology. 
Here we only discuss the influence of the expansive grout on the theoretical bandwidth of borehole tensor strainmeters, and prove the possibility of quantitative measuring of high-frequency seismic strain waves in theory. However, the actual situation is more complicated. It is necessary to do the job using the in situ observed data in the future.

Author Contributions: Conceptualization, J.T.; Methodology, J.T.; Software, K.Z.; Validation, J.T., K.Z. and Z.H.; Formal analysis, J.T.; Investigation, K.Z. and Z.H.; writing-original draft preparation, K.Z.; writing-review and editing, J.T.; Supervision, J.T.; Project administration, J.T.; Funding acquisition, J.T. All authors have read and agreed to the published version of the manuscript.

Funding: Institute of Crustal Dynamics, China Earthquake Administration (ZDJ2019-15-1 and ZDJ2018-22).

Acknowledgments: The authors kindly acknowledge the support of research grants from Institute of Crustal Dynamics, China Earthquake Administration (ZDJ2019-15-1 and ZDJ2018-22).

Conflicts of Interest: The authors declare no conflict of interest.

\section{References}

1. Linde, A.T.; Agustsson, K.; Sacks, I.S.; Stefansson, R. Mechanism of the 1991 eruption of Hekla from continuous borehole strain monitoring. Nature 1993, 365, 737-740. [CrossRef]

2. Gladwin, M.T.; Gwyther, R.L.; Hart, R.H.G.; Breckenridge, K.S. Measurements of the strain field associated with episodic creep events on the San Andreas fault at San Juan Bautista, California. J. Geophys. Res. Solid Earth 1994, 99, 4559-4565. [CrossRef]

3. Linde, A.T.; Gladwin, M.T.; Johnston, M.J.S.; Gwyther, R.L.; Bilham, R.G. A slow earthquake sequence on the San Andreas fault. Nature 1996, 383, 65-68. [CrossRef]

4. Langbein, J.; Gwyther, R.L.; Hart, R.H.G.; Gladwin, M.T. Slip-rate increase at Parkfield in 1993 detected by high-precision EDM and borehole tensor strainmeters. Geophys. Res. Lett. 1999, 26, 2529-2532. [CrossRef]

5. Ouyang, Z.X.; Zhang, H.X.; Fu, Z.Z.; Gou, B.; Jiang, W.L. Abnormal phenomena recorded by several earthquake precursor observation instruments before the M(s) 8.0 Wenchuan, Sichuan earthquake. Acta Geol. Sin. Engl. Ed. 2009, 83, 834-844. [CrossRef]

6. Smith, E.F.; Gomberg, J. A search in strainmeter data for slow slip associated with triggered and ambient tremor near Parkfield, California. J. Geophys. Res. Solid Earth 2009, 114, B00A14. [CrossRef]

7. Hawthorne, J.C.; Rubin, A.M. Tidal modulation of slow slip in Cascadia. J. Geophys. Res. Solid Earth 2010, 115, B09406. [CrossRef]

8. Agnew, D.C.; Wyatt, F.K. Dynamic strains at regional and teleseismic distances. Bull. Seismol. Soc. Am. 2014, 104, 1846-1859. [CrossRef]

9. Barbour, A.J.; Crowell, B.W. Dynamic strains for earthquake source characterization. Seismol. Res. Lett. 2017, 88, 354-370. [CrossRef]

10. Chi, S.L. Trial results of YRY-2 shallow borehole strainmeter at eight observation sites in North China. Earthq. Sci. 1993, 6, 731-737. [CrossRef]

11. Gladwin, M.T. High-precision multi-component borehole deformation montoring. Rev. Sci. Instrum. 1984, 55, 2011-2016. [CrossRef]

12. Gladwin, M.T.; Hart, R. Design parameters for borehole strain instrumentation. Pure Appl. Geophys. 1985, 123, 59-80. [CrossRef]

13. John, L. Computer algorithm for analyzing and processing borehole strainmeter data. Comput. Geosci. 2010, 36, 611-619. [CrossRef]

14. Langbein, J. Effect of error in theoretical earth tide on calibration of borehole strainmeters. Geophys. Res. Lett. 2010, 37, L21303. [CrossRef]

15. Roeloffs, E. Tidal calibration of Plate Boundary Observatory borehole strainmeters: Roles of vertical and shear coupling. J. Geophys. Res. Solid Earth 2010, 115, B06405. [CrossRef]

16. Hodgkinson, K.; Langbein, J.; Henderson, B.; Mencin, D.; Borsa, A. Tidal calibration of plate boundary observatory borehole strainmeters. J. Geophys. Res. Solid Earth 2013, 118, 447-458. [CrossRef]

17. Langbein, J. Borehole strainmeter measurements spanning the 2014 Mw6.0 South Napa earthquake, California: The effect from instrument calibration. J. Geophys. Res. Solid Earth 2015, 120, 7190-7202. [CrossRef]

18. Chi, S.L. China's component borehole strainmeter network. Earthq. Sci. 2009, 6, 579-587. [CrossRef] 
19. Li, H.L.; Li, H. Status and Developments of Borehole Strain Observation in China. Acta Geol. Sin. 2010, 84, 895-900.

20. Sato, T.; Harrison, J.C. Local effects on tidal strain measurements at Esashi, Japan. Geophys. J. Int. 1990, 102, 513-526. [CrossRef]

21. Hart, R.H.G.; Gladwin, M.T.; Gwyther, R.L.; Agnew, D.C.; Wyatt, F.K. Tidal calibration of borehole strain meters: Removing the effects of small-scale inhomogeneity. J. Geophys. Res. Solid Earth 1996, 101, 25553-25571. [CrossRef]

22. Sacks, I.S.; Snoke, J.A.; Evans, R.; King, G.; Beavan, J. Single-site phase velocity measurement. Geophys. J. R. Astron. Soc. 1976, 46, 253-258. [CrossRef]

23. Barbour, A.J.; Agnew, D.C. Detection of seismic signals using seismometers and strainmeters. Bull. Seismol. Soc. Am. 2012, 102, 2484-2490. [CrossRef]

24. Qiu, Z.H.; Chi, S.L.; Wang, Z.M.; Carpenter, S.; Tang, L.; Guo, Y.P.; Yang, G. The strain seismograms of Pand S-waves of a local event recorded by four-gauge borehole strainmeter. Earthq. Sci. 2015, 28, 209-214. [CrossRef]

25. Currenti, G.; Zuccarello, L.; Bonaccorso, A.; Sicali, A. Borehole Volumetric Strainmeter Calibration From a Nearby Seismic Broadband Array at Etna Volcano. J. Geophys. Res. Solid Earth 2017, 122, 7729-7738. [CrossRef]

26. Ishii, M.; Park, S. Near-surface compressional and shear wave speeds constrained by body-wave polarization analysis. Geophys. J. Int. 2018, 213, 1559-1571. [CrossRef]

27. Zhang, K.; Tian, J.; Hu, Z. Theoretical frequency response bandwidth of empty borehole for the measurement of strain waves in borehole tensor strainmeters. Bull. Seismol. Soc. Am. 2019, 109, 2459-2469. [CrossRef]

28. Pao, Y.-H.; Mow, C.-C. Diffraction of Elastic Waves and Dynamics Stress Concentrations; Crane Russak: New York, NY, USA, 1971.

29. Cheng, D.X. Mechanical Design Handbook; Chemical Industry Press: Beijing, China, 2004.

(C) 2020 by the authors. Licensee MDPI, Basel, Switzerland. This article is an open access article distributed under the terms and conditions of the Creative Commons Attribution (CC BY) license (http://creativecommons.org/licenses/by/4.0/). 